\title{
Benchmark and Partial Validation Testing of the Flash Computer Code Version 3.0
}

\author{
Pote Martlan \\ Cary S. Smith
}

Publishod September 1993

\author{
Idaho National Engineering Laboratory \\ EG\&G Idaho, Inc. \\ Idaho Falls, Idaho $\mathbf{8 3 4 1 5}$
}

\section{Prepared for the}

U.S. Department of Energy

Assistant Secretary for Environmental Restoration and Waste Management Under DOE Idaho Operations Office

Contract No. DE-AC07-761D01570 


\begin{abstract}
This document presents methods and results of benchmark testing (i.e., code-to-code comparisons) and partial validation testing (i.e., tests which compare field data to the computer generated solutions) of the FLASH computer code, Version 3.0, which were conducted to determine if the code is ready for performance assessment studies of the Radioactive Waste Management Complex.

Three test problems are presented that were designed to check computational efficiency, accuracy of the numerical algorithms, and the capability of the code to simulate diverse hydrological conditions. These test problems were designed to specifically test the code's ability to simulate, (a) seasonal infiltration in response to meteorological conditions, (b) changing watertable elevations due to a transient areal source of water, (i.e. influx from spreading basins), and (c) infiltration into fractured basalt as a result of seasonal water in drainage ditches.
\end{abstract}

The FLASH simulations generally compared well with the benchmark codes, indicating good stability and acceptable computational efficiency while simulating a wide range of conditions. The code appears operational for modeling both unsaturated and saturated flow in fractured, heterogeneous porous media. However, the code failed to converge when a unsaturated to saturated transition occurred. Consequently, the code should not be used when this condition occurs or is expected to occur, i.e. when perched water is present or when infiltration rates exceed the saturated conductivity of the soil. 


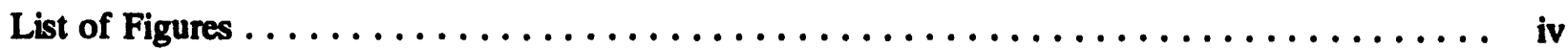

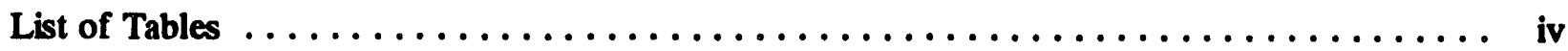

1.0 INTRODUCTION $\ldots \ldots \ldots \ldots \ldots \ldots \ldots \ldots \ldots \ldots \ldots \ldots \ldots \ldots \ldots \ldots \ldots$

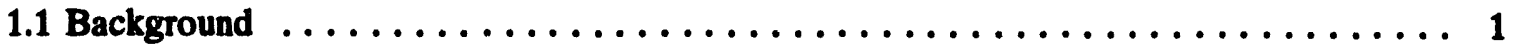

1.2 Purpose and Objective $\ldots \ldots \ldots \ldots \ldots \ldots \ldots \ldots \ldots \ldots \ldots \ldots \ldots \ldots \ldots$

1.3 Computational Testing $\ldots \ldots \ldots \ldots \ldots \ldots \ldots \ldots \ldots \ldots \ldots \ldots \ldots \ldots$

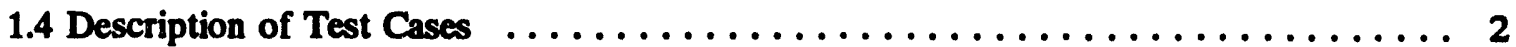

2.0 TEST APPROACH AND REQUIREMENTS $\ldots \ldots \ldots \ldots \ldots \ldots \ldots \ldots \ldots \ldots$

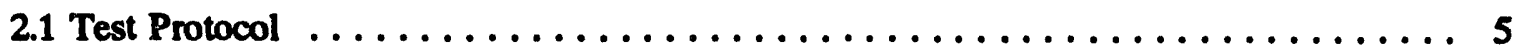

2.2 Performance Evaluation $\ldots \ldots \ldots \ldots \ldots \ldots \ldots \ldots \ldots \ldots \ldots \ldots \ldots \ldots$

3.0 BENCHMARK TESTS $\ldots \ldots \ldots \ldots \ldots \ldots \ldots \ldots \ldots \ldots \ldots \ldots \ldots \ldots \ldots \ldots$

3.1 Seasonal Infiltration in Response to Meterological Conditions $\ldots \ldots \ldots \ldots \ldots \ldots$

3.2 Transient Free-Surface Flow in Response To Spreading Area Discharge . . . . . . . . 18

3.3 Transient Infiltration from Surface Ditches $\ldots \ldots \ldots \ldots \ldots \ldots \ldots \ldots \ldots \ldots$

4.0 FINDINGS AND RECOMMENDATIONS $\ldots \ldots \ldots \ldots \ldots \ldots \ldots \ldots \ldots \ldots \ldots \ldots \ldots \ldots$

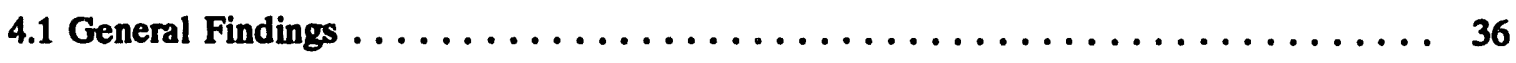

4.2 Recommended Refinements .......................... 37

4.3 Recommendations for Additional Testing $\ldots \ldots \ldots \ldots \ldots \ldots \ldots \ldots$

REFERENCES $\ldots \ldots \ldots \ldots \ldots \ldots \ldots \ldots \ldots \ldots \ldots \ldots \ldots \ldots \ldots \ldots \ldots \ldots \ldots$

APPENDIX A $\ldots \ldots \ldots \ldots \ldots \ldots \ldots \ldots \ldots \ldots \ldots \ldots \ldots \ldots \ldots \ldots \ldots \ldots \ldots$ 


\section{List of Figures}

Location of the Radioactive Waste Management Complex $\ldots \ldots \ldots \ldots \ldots \ldots \ldots \ldots \ldots$

Soil Profile Cross-sections $\ldots \ldots \ldots \ldots \ldots \ldots \ldots \ldots \ldots \ldots \ldots \ldots \ldots \ldots \ldots$

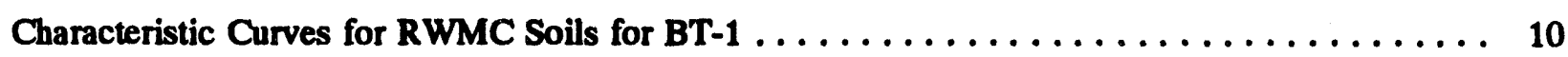

BT-1 Measured and Simulation Initial Conditions $\ldots \ldots \ldots \ldots \ldots \ldots \ldots \ldots \ldots \ldots$

BT-1 Soil Moisture Profile for May $7,1987 \ldots \ldots \ldots \ldots \ldots \ldots \ldots \ldots \ldots \ldots$

BT-1 Soil Moisture Profile for July $26,1988 \ldots \ldots \ldots \ldots \ldots \ldots \ldots \ldots \ldots \ldots \ldots$

BT-1 Soil Moisture Profile for October 4, $1988 \ldots \ldots \ldots \ldots \ldots \ldots \ldots \ldots \ldots \ldots$

BT-1 Soil Moisture Profile for February $23,1989 \ldots \ldots \ldots \ldots \ldots \ldots \ldots \ldots \ldots \ldots \ldots$

BT-1 Soil Moisture Profile for March 26, $1990 \ldots \ldots \ldots \ldots \ldots \ldots \ldots \ldots \ldots \ldots$

BT-1 Soil Moisture Profile for August $2,1990 \ldots \ldots \ldots \ldots \ldots \ldots \ldots \ldots \ldots \ldots$

BT-2 Finite Element Grid for FLASH, and Finite Difference Grid for PORFLOW . . . . . 20

BT-2 Initial Steady-State Pressure Field $\ldots \ldots \ldots \ldots \ldots \ldots \ldots \ldots \ldots \ldots \ldots \ldots \ldots \ldots$

BT-2 Aquifer Depth $(m)$ for December, $1984 \ldots \ldots \ldots \ldots \ldots \ldots \ldots \ldots \ldots \ldots$

BT-2 Increase in Aquifer Depth $(m)$ for December, $1984 \ldots \ldots \ldots \ldots \ldots \ldots \ldots$

BT-2 Aquifer Depth $(\mathrm{m})$ for December, $1986 \ldots \ldots \ldots \ldots \ldots \ldots \ldots \ldots \ldots$

BT-2 Increase in Aquifer Depth $(\mathrm{m})$ for December, $1986 \ldots \ldots \ldots \ldots \ldots \ldots \ldots$

BT-2 Aquifer Depth $(\mathrm{m})$ for December, $1993 \ldots \ldots \ldots \ldots \ldots \ldots \ldots \ldots \ldots \ldots$

BT-2 Increase in Aquifer Depth $(\mathrm{m})$ for December, $1993 \ldots \ldots \ldots \ldots \ldots \ldots$

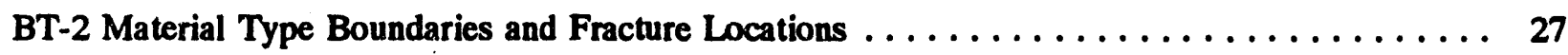

BT-3 Finite Element Grid for FLASH, and Finite Difference Grid for PORFLOW . . . . . . 30

BT-3 Decrease in Pressure from Wetting Front Advance at the Beginning of the 3rd Year . . . . 33

BT-3 Decrease in Pressure Head from Wetting Front Advance at the End of the 5th Year ..... 34

BT-3 Pressure Fields at the End of Simulation $\ldots \ldots \ldots \ldots \ldots \ldots \ldots \ldots \ldots \ldots \ldots$

\section{Ust of Tables}

BT-1 van Genuchten Parameters for RWMC Surficial Sediments $\ldots \ldots \ldots \ldots \ldots \ldots \ldots$

BT-1 Sources of Meteorologic Data for Simulation Period $\ldots \ldots \ldots \ldots \ldots \ldots \ldots \ldots$

BT-1 Yearly Recharge and Precipitation $\ldots \ldots \ldots \ldots \ldots \ldots \ldots \ldots \ldots \ldots \ldots \ldots \ldots$

BT-3 Material Hydraulic Parameters $\ldots \ldots \ldots \ldots \ldots \ldots \ldots \ldots \ldots \ldots \ldots \ldots \ldots$ 


\subsection{INTRODUCTION}

The Radioactive Waste Management Complex (RWMC) is located in the southwest portion of the Idaho National Engineering Laboratory, (see Figure 1). Low-level, mixed, and transuranic radioactive wastes were disposed in shallow pits and trenches at the RWMC from the early 1950s until 1970. Subsequent to 1970, only low-level wastes were disposed, and this practice continues to the present time. As a result of DOE Order 5820.2A, a performance assessment is being conducted on the low-level waste facility at the RWMC (Case, et al., 1990).

\subsection{Background}

The performance assessment for the RWMC is, in part, based on predictions of infiltrating moisture flow and radionuclide transport through the vadose zone down to the regional Snake River Plain Aquifer. These predictions have been rather simplistic in their representation of flow through the subsurface as having a uniform constant velocity. The FLASH computer code (Baca and Magnuson, 1992) has been developed for use in more representative flow simulations of the vadose zone as data become available to justify their use. It is anticipated that future performance assessment simulations will include the effect of fractures separately from the basalt matrix, sedimentary interbeds, and timevariant infiltration at the surface to include seasonal infiltration and flooding conditions.

\subsection{Purpose and Objective}

The FLASH code has undergone verification and limited validation testing (Martian and Chung, 1992). To complete the development cycle, this document details a benchmarking study of the FLASH computer code. Benchmarking refers to a direct code-to-code comparison of simulation results on equivalent problems. A successful comparison between results ensures that the computer code is solving the governing equations comparably against other codes with similar capabilities. If the simulation results are also representative of an actual field situation for which measurements exist, the problem can also be used to demonstrate the validity of the modeling approach.

\subsection{Computational Testing}

The computational testing in this report closely follows that approach used by Magnuson et al. (1990). A simulation was said to be benchmarked when its results showed reasonable agreement with simulations obtained from another computer code of similar capability. Three benchmarking exercises 
were designed to test the different abilities of FLASH. For each benchmark (BT), test the results from FLASH were compared to those of another established computer model.

\subsection{Description of Test Cases}

Three simulations related to the movement of water in the subsurface at the RWMC were simulated. Each problem is quite complex in differing ways. The simulations ranged from seasonal infiltration in response to precipitation, to localized fluctuations of the aquifer level due to water being diverted from the Big Lost River to the spreading areas during high runoff years, and to pulses of water moving through the near-surface in response to spring snowmelt being carried away in surfaces ditches around the RWMC. Each of these problems will be discussed briefly.

\section{Seasonal Infiltration In Response to Meteorological Conditions (BT-1)}

In this problem, the FLASH code simulated the changes of the moisture content in the near surface soils of the RWMC as infiltrating moisture percolates down to the aquifer. Since FLASH does not contain an algorithm to estimate evaporation in response to meteorological conditions, the UNSAT-H code (Fayer and Jones, 1986) was used both to provide the time-dependent variable flux upper boundary condition for the FLASH simulation and to be the benchmark code to compare against FLASH. Field measurements of moisture content profiles inside the RWMC (McElroy, 1990) were also compared against the FLASH and UNSAT-H simulation results and thus serve the additional purpose of validating this particular simulation problem.

\section{Transient Free-Surface Flow in Response to Spreading Area Discharge (BT-2)}

The INEL diversion system was utilized for several years in the early 1980 s to divert water from the Big Lost River to the Spreading Areas (Wood, 1989). The majority of this diverted water infiltrated into the regional aquifer, and the resulting mound caused streamlines to differ by up to 90 degrees from the normal flow direction. FLASH was used to simulate the aquifer during the high influx period caused by additional infiltration from the water diverted to the spreading areas, and the aquifer's return to normal levels. PORFLOW (Runchal and Sagar, 1993) was used as the benchmark code because it also has the ability to simulate an aquifer with a varying depth. 


\section{Transient Infiltration From Surface Ditches (BT-3)}

In this problem, seasonal infiltration due to water being present in drainage ditches on the RWMC was simulated with the FLASH code. A two-dimensional vertical problem was simulated with a representative ditch at the surface. The subsurface was represented by surficial sediments, basalt flows, and sedimentary interbeds. Additionally, a regularly-spaced fracture network was superimposed on the basalt in order to test this feature of the FLASH code. The PORFLOW code uses a similar method to superimpose fractures and thus is a good benchmarking code for this problem. 


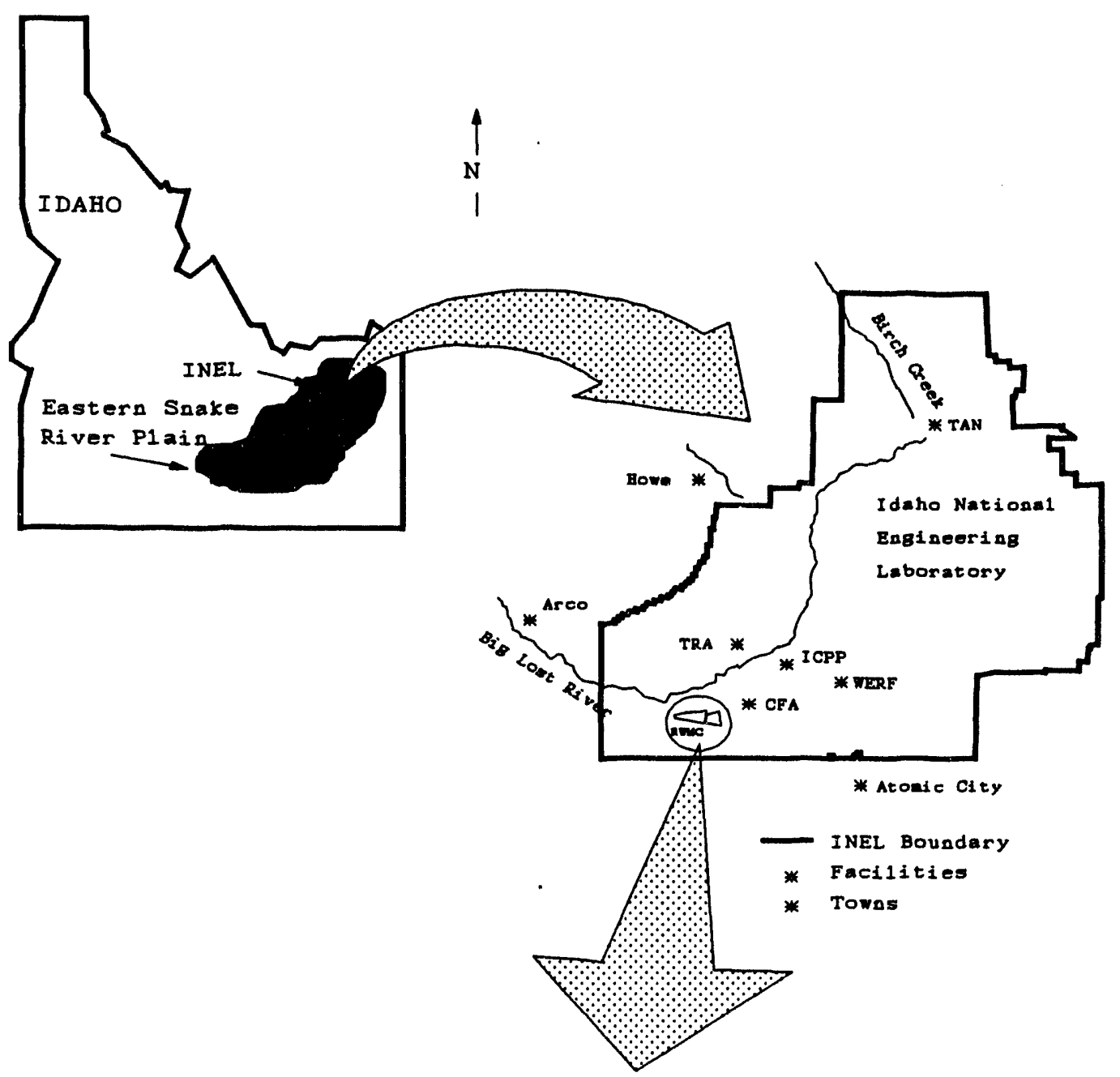

Radioactive Waste Management Complex

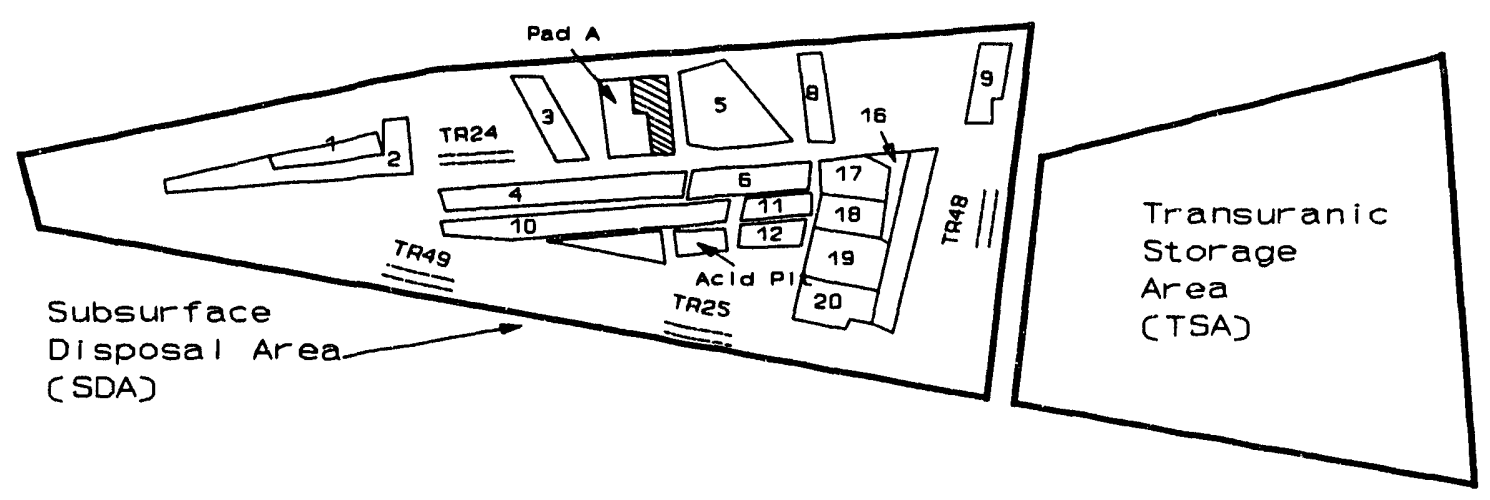

Figure 1. Location of the Radioactive Waste Management Complex. 


\subsection{TEST APPROACH AND REQUIREMENTS}

\subsection{Test Protocol}

The benchmarking process was designed to be an independent and unbiased evaluation of FLASH, Version 3.0. To perform the testing process, a convention using the following requirements was employed:

- Independent applications

- Test equivalence.

The first requirement excluded the code developer from participating in the testing process. The code tester was permitted to consult the code developer only if (a) unexplained difficulties arose, (b) code modifications were necessary to accommodate special characteristics of a specific test problem, or (c) clarification of input instructions was needed.

The second requirement was that each code use the same or similar spatial discretization for each test problem. Some latitude in spatial discretization was necessary because of the different computational methods used in the tested and benchmarking codes, i.e., finite elements vs. finite differences. The purpose of the requirement was to require that a similar amount of computational effort be expended and provide a similar representation of the modeled processes. However, no constraints were placed on the time discretization, i.e., time step size, because all the benchmark codes utilize an automatic time-step control.

\subsection{Performance Evaluation}

Quantitatively judging the quality of benchmark tests can be difficult because the results are only approximate solutions to the governing equations. Numerical differences between simulation results often reflect algorithm and different approximation approaches. An example is the different way the benchmark codes compute interfacial hydraulic conductivities, i.e., hydraulic conductivities at soil-type interfaces between grid nodes. Both the PORFLOW and UNSATH codes use an arithmetic, geometric, or harmonic mean, depending on the user's specification. Past researchers have shown that the specific method chosen can have a significant effect on the numerical solutions (Schnabel and Richie, 1984; Pantankar, 1980; and Crichlow, 1977). Finite element codes like the FLASH code do not use the concept of interfacial conductivity as the hydraulic conductivity is discontinuous between elements at soil-type interfaces.

Because significant differences were expected in the results from FLASH and the benchmark 
codes, graphical comparisons were made for such variables as pressure head and volumetric moisture content. 


\subsection{BENCHMARK TESTS}

\subsection{Seasonal Infiltration in Response to Meteorological Conditions}

\subsubsection{Problem Statement for BT-1}

This benchmark problem considers moisture movement in the surficial sediments of the RWMC. During the period between 1985 and 1987, a network of vadose zone instruments were installed at the RWMC and a monthly monitoring program was started (McElroy, 1990). The various instruments installed at the RWMC included neutron access boreholes W02 and W06, which are located near the northeast and southeast boundaries of the subsurface disposal area. The neutron access monitoring system was used to measure insitu moisture contents, and readings were taken on approximately a monthly basis at 6-in intervals from the soil surface to the basalt bedrock. Data collected at the RWMC show the seasonal pattern of infiltration at the RWMC. To observe this seasonal pattern in a numerical simulation, water movement at borehole W06 is modeled over a 5-year period, from 1986 to 1990.

\subsubsection{Test Objectives}

The objective of this test was io evaluate how well the FLAS' code models fluctuating water patterns in surficial sediments under variably saturated conditious. Moisture contents computed by the FLASH code are compared with those from another computer code as well as with field measurements gathered using the neutron logging equipment. The test problem also checks whether the seasonal infiltration patterns at the RWMC can be reasonably modeled and serves as a validation of the FLASH code.

\subsubsection{Computer Code Used}

The UNSATH computer code (Fayer et al., 1986) was chosen for comparison with the FLASH code because of its ability to model infiltration as a function of meteorological conditions. One-dimensional movement of water in either the vertical or horizontal direction may be modeled. Specifically, the code has the ability to account for.

- Liquid and vapor water movent

- Heat transfer by conduction and convection

- Evapotranspiration at the soil surface

- Transpiration by plants. 
The code uses an iterative finite difference technique to solve the governing equations for these processes.

\subsubsection{Input Specincations}

The model domain consists of a one-dimensional vertical column. Four soil types are used in the domain discretized by 113 nodes in the FLASH simulation and 105 nodes in the UNSATH simulation. Nodal spacings were set relatively close together at the soil surface and were then lengthened with increasing soil depth. The same nodal locations were used in both simulations except in some instances when additional nodes were required at element boundaries in the FLASH code. These additional nodes were needed when element boundaries did not coincide with soil-type interfaces, because all nodes in any one finite element must be of the same soil type.

Laboratory analysis of core samples taken from the RWMC surficial sediments (McElroy and Hubbell, 1990) indicate that a slightly lower conductivity soil is present approximately 2 to $3 \mathrm{ft}$ below the surface and is present again at approximately $7 \mathrm{ft}$ below the surface to the basalt-surficial sediment interface. Soil moisture profiles taken from neutron probe measurements also reflect this trend. Slightly higher moisture contents were observed near the soil surface and again near soil-bedrock interface. Low conductivity zones in soils typically have a higher moisture content because water tends to accumulate in these regions as the downward movement of water may be restricted by these low conductivity zones.

Using these observations, soil properties were assigned to the regions of lower and higher conductivity from core sample analysis by McElroy and Hubbell (1990). Additionally, two transition regions were defined between the relatively low conductivity zone and higher conductivity regions. The soil hydraulic parameters in these transitions were defined by interpolating between the hydraulic properties of the relatively low and high conductivity regions. A cross section of the domain is depicted in Figure 2. The hydraulic parameters used in the simulation are given in Table 1, and the characteristic curves for the soil are illustrated in Figure 3. 
Table 1. BT-1 van Genuchten parameters for RWMC surficial sediments.

\begin{tabular}{ccccccc}
\hline Soil layer & $\begin{array}{c}\mathrm{K} \\
(\mathrm{cm} / \mathrm{hr})\end{array}$ & $\theta_{\mathrm{s}}$ & $\theta_{\mathrm{r}}$ & \multicolumn{2}{c}{$\begin{array}{c}\alpha \\
(1 / \mathrm{cm})\end{array}$} & \\
\hline 1 & 0.62 & 0.51 & 0.12 & 0.01197 & 1.58911 \\
2 & 0.48 & 0.507 & 0.127 & 0.01033 & 1.58461 \\
3 & 0.35 & 0.503 & 0.133 & 0.00869 & 1.58011 \\
4 & 0.21 & 0.50 & 0.14 & 0.00705 & 1.57561 \\
\hline
\end{tabular}

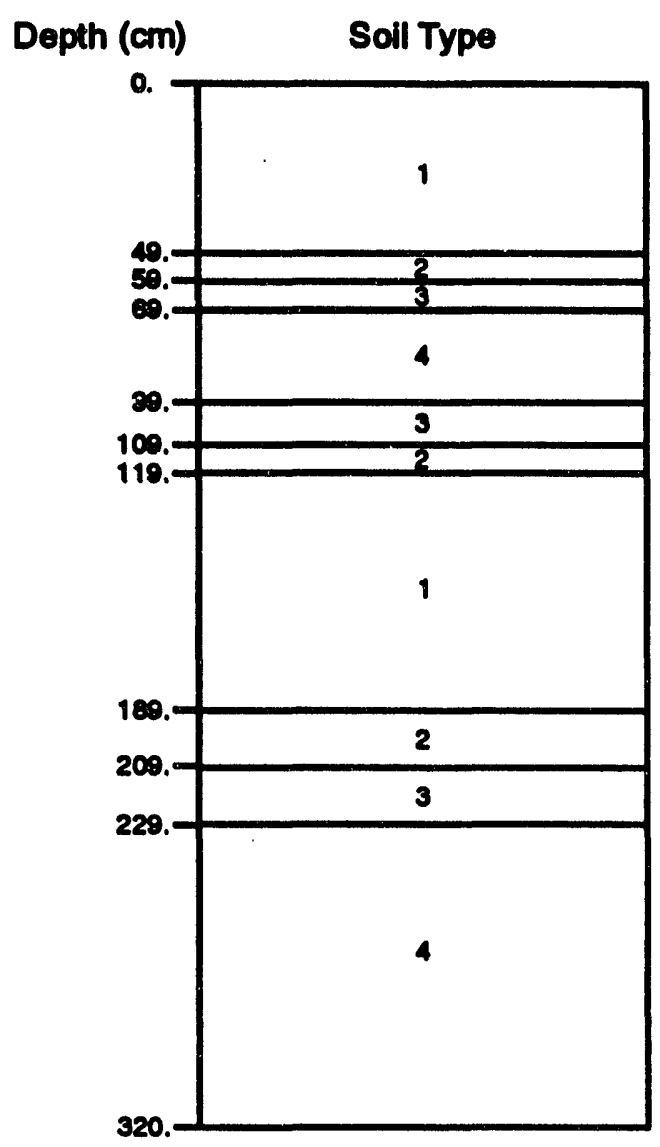

Figure 2. Soil profile cross-sections for BT-1. 


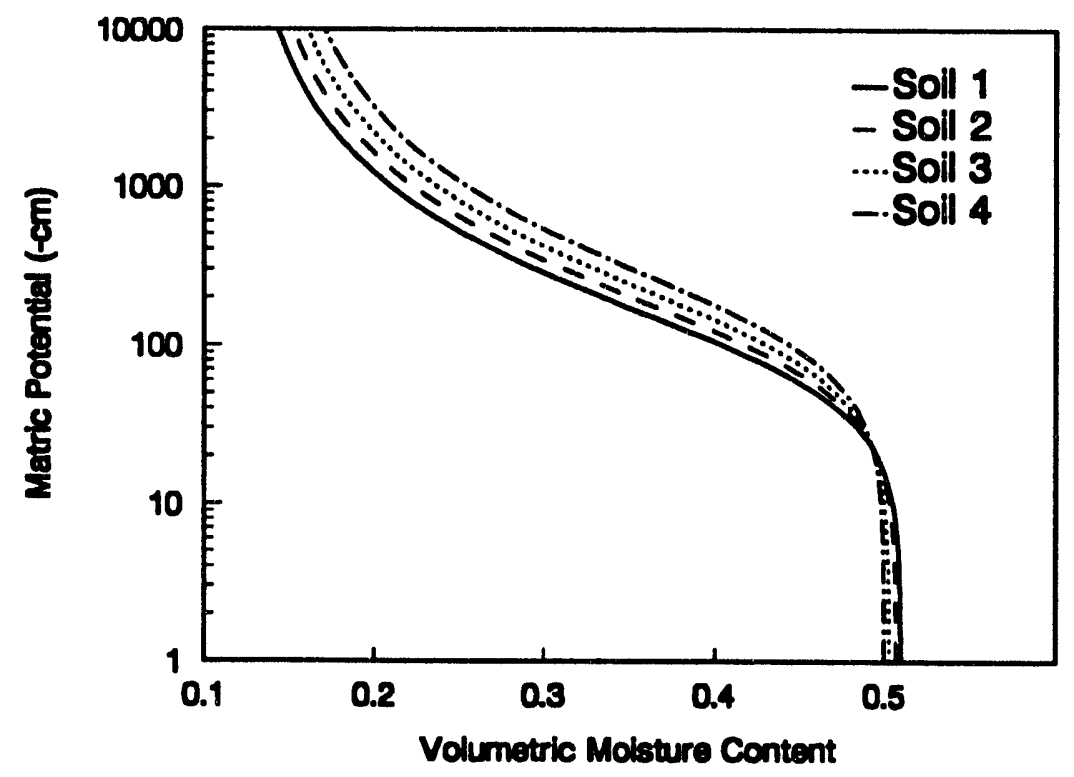

Figure 3. Characteristic curves for RWMC soils for BT-1.

The observed moisture contents from neutron probe measurements were also used to estimate the initial conditions in the modeled soil profile. Measurements from January 1986 showed a very general trend of increasing saturation with increasing soil depth, and this trend was used to estimate a linear distribution of initial moisture content in the modeled profile. A moisture content of $15 \%$ was assigned at the soil surface, while a moisture content of $35 \%$ was specified at the basalt-soil interface. The matric potential corresponding to these moisture contents at each node was then estimated by inversely solving the Van Genuchten (1990) relation

$$
\theta(h)=\theta_{x}+\frac{\left(\theta_{e}-\theta_{x}\right)}{\left(1+a|h|^{b}\right)^{-}}
$$

where

$\theta_{\mathrm{s}}=$ porosity,

$\theta_{\mathrm{r}}=$ residual water content,

$\mathrm{h}=$ is matric potential, 


$$
\begin{aligned}
& a=\text { inverse air entry head, } \\
& b=\text { pore size distribution index and } \\
& m=1-1 / b .
\end{aligned}
$$

The modeled initial saturations along with the measured moisture contents are shown in Figure 4.

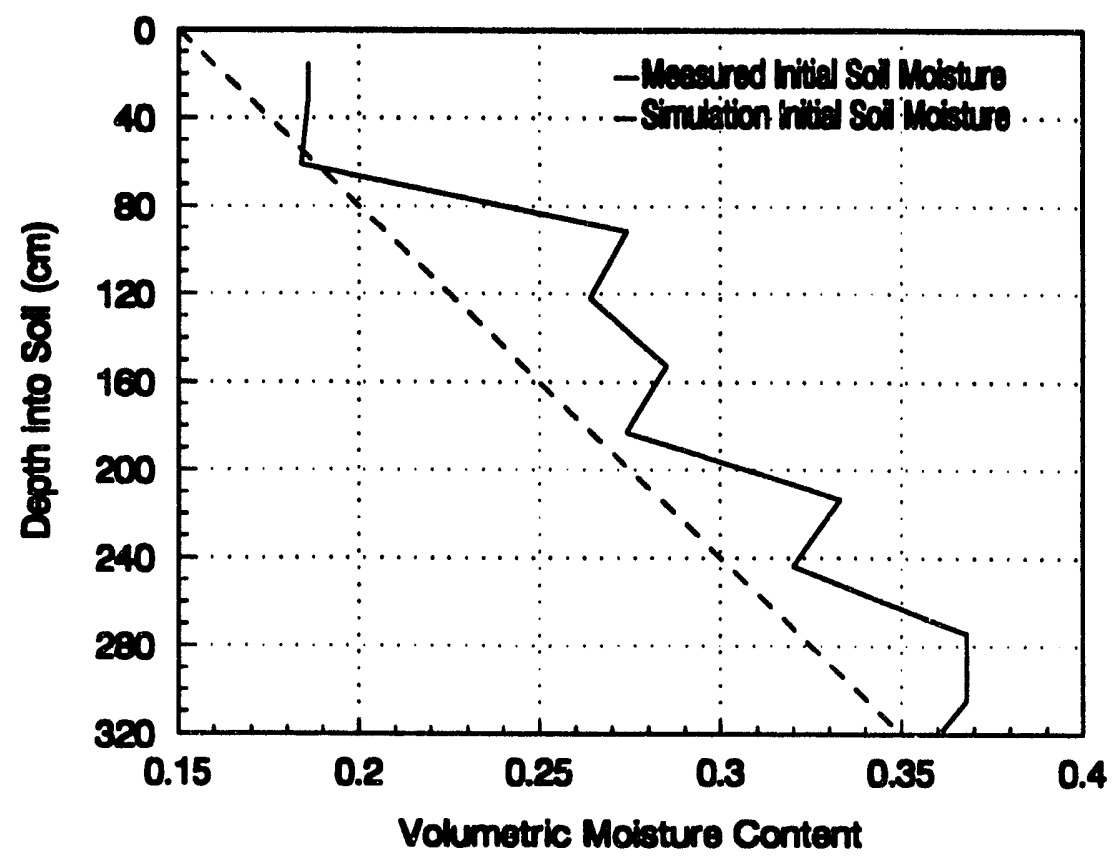

Figure 4. BT-1 measured and simulation initial conditions.

Recharge events at the RWMC usually occur in the early spring, and individual recharge events have been documented by McElroy (1990) during the months of March and April. Early spring rains and snowmelt were found primarily responsible for all recharge occurring at the RWMC. To simulate the annual cycles of wetting and drying in the RWMC surficial sediments, the UNSATH code was used to generate daily infiltration or evaporation rates for use as a time-varying flux boundary condition at the soil surface in the FLASH simulation. The bottom boundary condition was specified as a unit gradient, allowing free drainage from the soil profile.

The UNSATH code requires site-specific meteorologic data in order to determine infiltration and evaporation rates at the soil surface. The meteorologic parameters required are maximum and minimum air temperature, dewpoint temperature, solar radiation, average wind speed, average cloud cover, and daily precipitation. The majority of this meteorologic data was obtained from the National 
Oceanographic and Aeronautic Administration weather station at the Central Facilities Area (CFA), which is located approximately $5.5 \mathrm{mi}$ from the RWMC. However, ccnsistent data from the CFA were available for only temperature, wind speed and precipitation. The remaining data were obtained from either the National Weather Service station at the Pocatello airport, located 60 mi southeast of the RWMC, or it was synthetically generated using the WGEN program (Richardson and Wright, 1984). The sources for meteorologic data used during the 5 year simulation are presented in Table 2. A correlation study between meteorologic data collected at the RWMC and other locations on the Snake River Plain was conducted by Magnuson (1993). This study consists of graphical and statistical comparisons between data from various sites and provides the basis for using weather data from sites other than the United States Geological Survey micro weather station located at the RWMC for infiltration studies performed for the RWMC.

Table 2. BT-1 sources of meteorologic data for simulation period.

\begin{tabular}{llllllll}
\hline Year & Temperature & Dew Pt. & Radiation & Wind Speed & Cloud Cover & Precipitation \\
\hline 1986 & CFA & Pocatello & WGEN & CFA & Pocatello & CFA \\
1987 & CFA & CFA & WGEN & CFA & Pocatello & CFA \\
1988 & CFA & CFA & WGEN & CFA & Pocatello & CFA \\
1989 & CFA & CFA & WGEN & CFA & Pocatello & CFA \\
1990 & CFA & CFA & WGEN & CFA & Pocatello & CFA \\
\hline
\end{tabular}

\subsubsection{Output Requirements}

Moisture content profiles computed with FLASH and UNSATH were compared graphically at representative days throughout the simulation period. In addition, insitu moisture contents measured with neutron logging equipment are included in the graphical comparisons for a validation of the FLASH code.

\subsubsection{Benchmark Results}

The results from BT-1 illustrate the seasonal pattern of infiltration at the RWMC and the annual pattern of drying and wetting near the soil surface. Figures 5 through 10 illustrate the soil 
moisture content as a function of depth for various days throughout the simulation period. The days chosen reflect the overall trends and provide a representative view of the changing soil moisture contents throughout the simulation period.

The moisture content profiles produced by the UNSATH and FLASH codes agree very well throughout the simulation period. There is only a slight disagreement early in the simulation period and again near the simulation end. The FLASH moisture contents tend to be slightly lower near the simulation start and near the simulation end. Also, in the top $60 \mathrm{~cm}$ of the profile, the depth vs. moisture content profiles from the two codes tend to have a slightly different shape. Some of the discrepancies between the two codes may be attributed to the different manner in which the upper boundary condition was imposed. The UNSATH code applies precipitation at a rate $1 \mathrm{~cm} / \mathrm{hr}$ starting at 0000 hours (midnight) until the entire daily precipitation record has been applied. The daily evapotranspiration amounts are distributed as a sine wave between the hours of 0600 and 1800 . The upper boundary condition in the FLASH code was implemented by evenly distributing the sum of daily infiltration and evaporation generated by the UNSATH code over the entire day. By distributing the precipitation amounts over an entire day, the top boundary in the FLASH code was prevented from approaching saturation. Benchmark problem 3.3, (discussed later) has shown that the FLASH code fails to converge at the unsaturated-to-saturated transition.

The numerical simulations generally had good agreement with the field measurements during the early spring and summer months, but had poor agreement during the fall and winter months. The numerical simulations predicted soil moisture contents to be significantly higher in the top half of the modeled profile during the late summer to early winter months. This trend can be seen in Figures 6 through 8, which are representative for the months of July, October, and February.

The prediction of the net downward flux through the vadose zone is an important aspect of contaminant transport and groundwater modeling. It can be thought of as the aquifer recharge and is critical in predicting whether contaminants stored in the vadose zone will be transported to the aquifer. While the FLASH code provides no practical means of extracting this value, the UNSATH code predicted the average recharge over the 5 year simulation period to be $1.7 \mathrm{~cm} / \mathrm{yr}$. A yearly summazy including precipitation totals is provided in Table 3. The unusually high recharge in 1986 is likely a result of the imposed initial conditions in the simulation.

The only unresolved problem encountered during BT-1 was the variable time-step algorithm, which increases or decreases the time step in accordance with solution parameters. While this feature can greatly reduce simulation computational time, it would increase the time step beyond the length of 
individual rainfall or evaporation periods and "over-step" these intervals. This problem was temporarily fixed by "hard wiring" a maximum time step into the code.

Table 3. Yearly recharge and precipitation from BT-1.

\begin{tabular}{lll}
\hline Year & $\begin{array}{l}\text { Rainfall } \\
(\mathrm{cm})\end{array}$ & $\begin{array}{l}\text { Recharge } \\
(\mathrm{cm})\end{array}$ \\
\hline 1986 & 33.0 & 3.05 \\
1987 & 19.8 & 1.72 \\
1988 & 9.55 & 1.36 \\
1989 & 21.1 & 1.16 \\
1990 & 17.1 & 1.34 \\
\hline
\end{tabular}

The FLASH and UNSATH simulations were run on a Hewlett Packard 730 workstation. Executions times were 3 hours 38 minutes for the FLASH run and 6 hours 43 minutes for the UNSATH run. These results indicate FLASH may be more efficiently programmed than the UNSATH code. However, no definite conclusions can be drawn because the UNSAT-H code utilizes a selfadjusting time step while the FLASH code was temporarily "hard wired" to use a 0.1-hour maximum time step.

In conclusion, the results of BT-1 showed that the FLASH code had good agreement with the benchmark code and fair agreement with the field measurements. The success encountered in calibrating the numerical models during the wetter spring months indicate that the RWMC can be successfully modeled but further calibration studies need to be performed on the models used in RWMC infiltration simulations. 


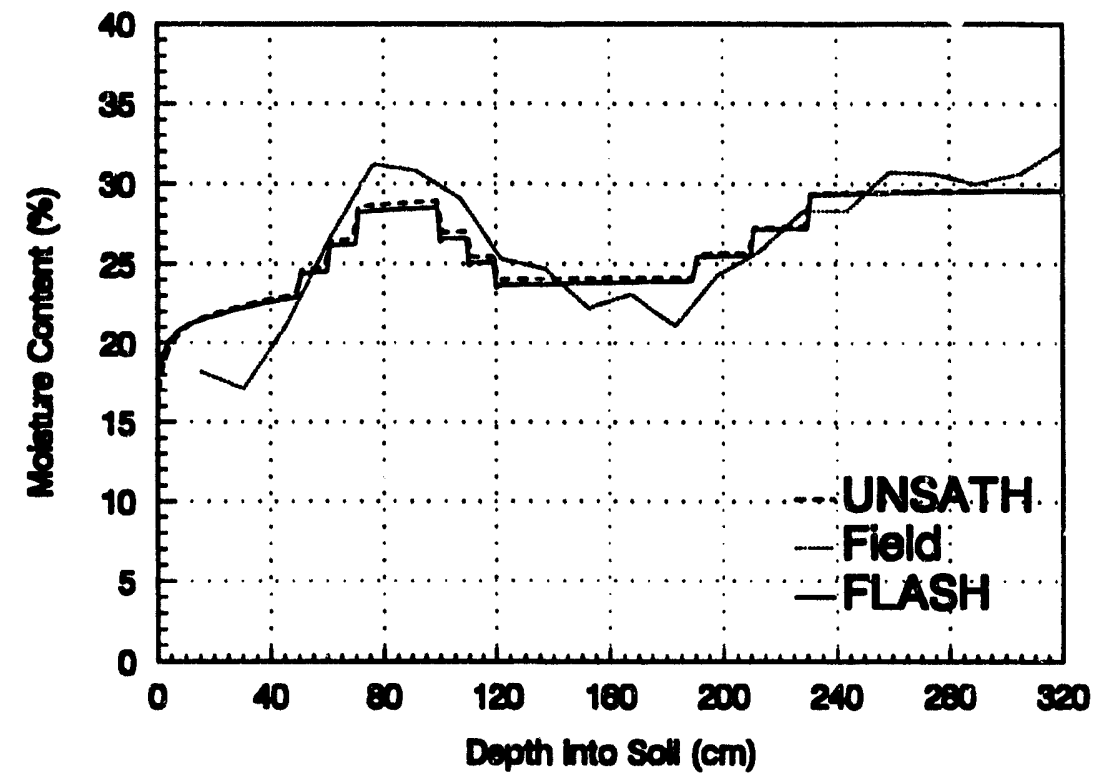

Figure 5. BT-1 soil moisture profile for May 7, 1987.

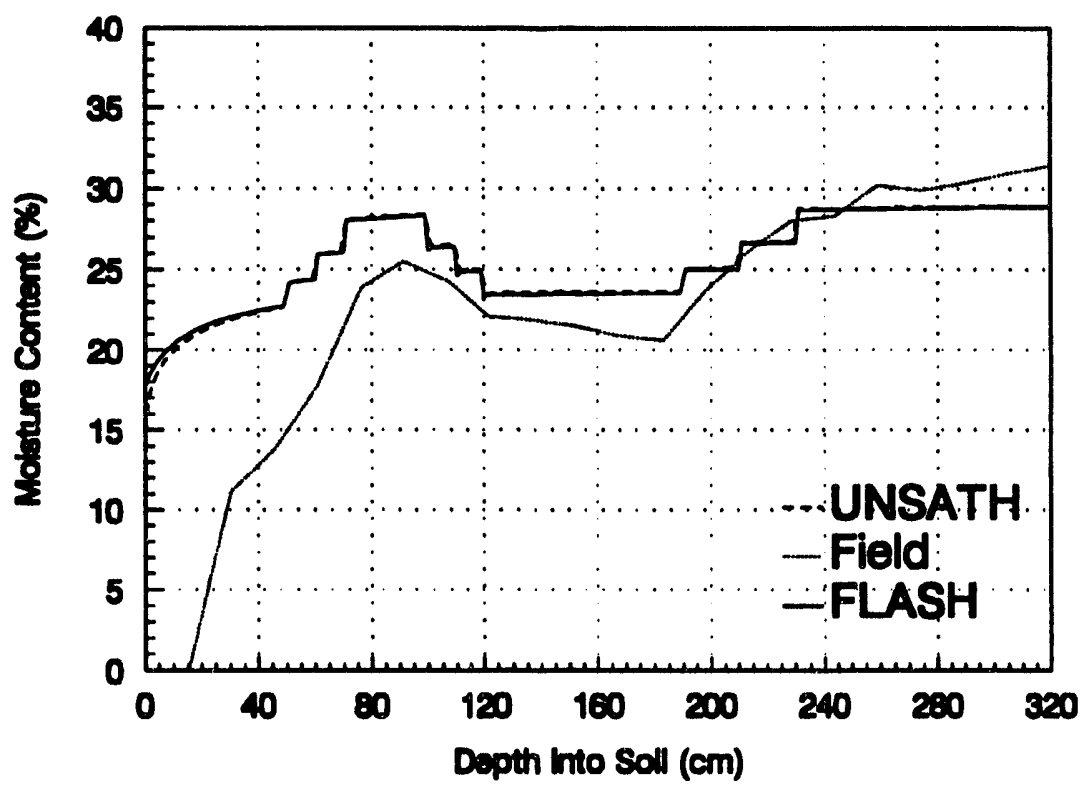

Figure 6. BT-1 soil moisture profile for July 26, 1988. 


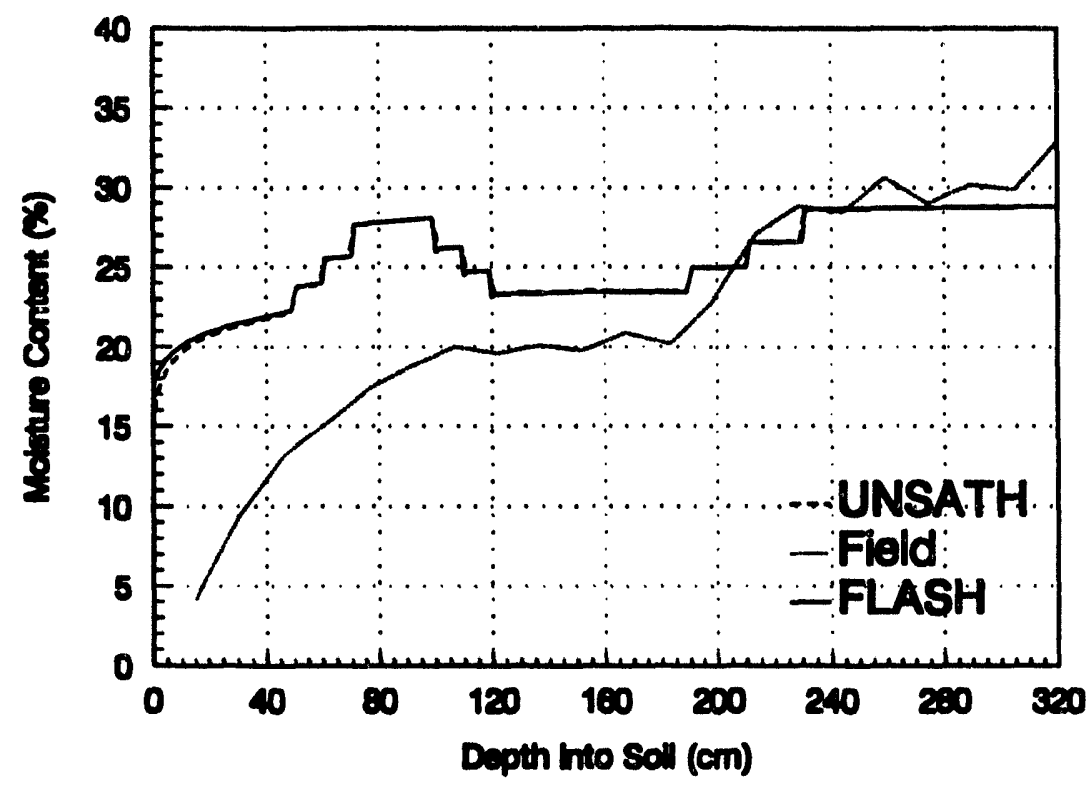

Figure 7. BT-1 soil moisture profile for October 4, 1988.

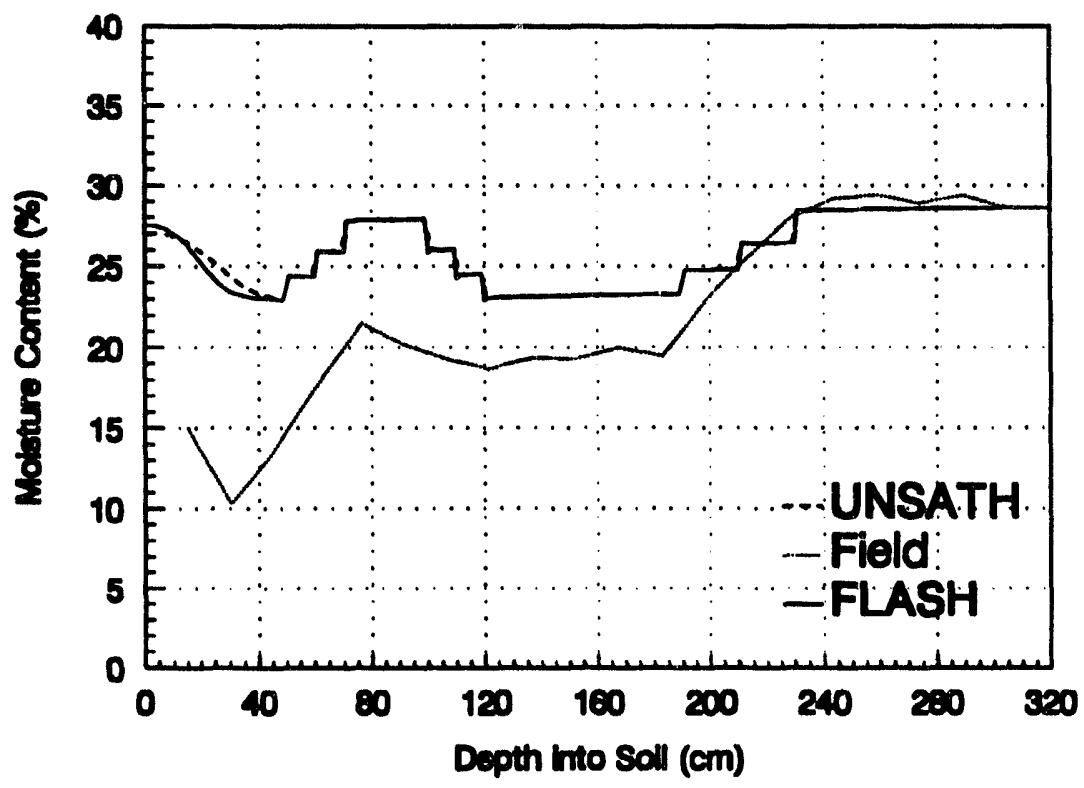

Figure 8. BT-1 soil moisture profile for February 23, 1989. 


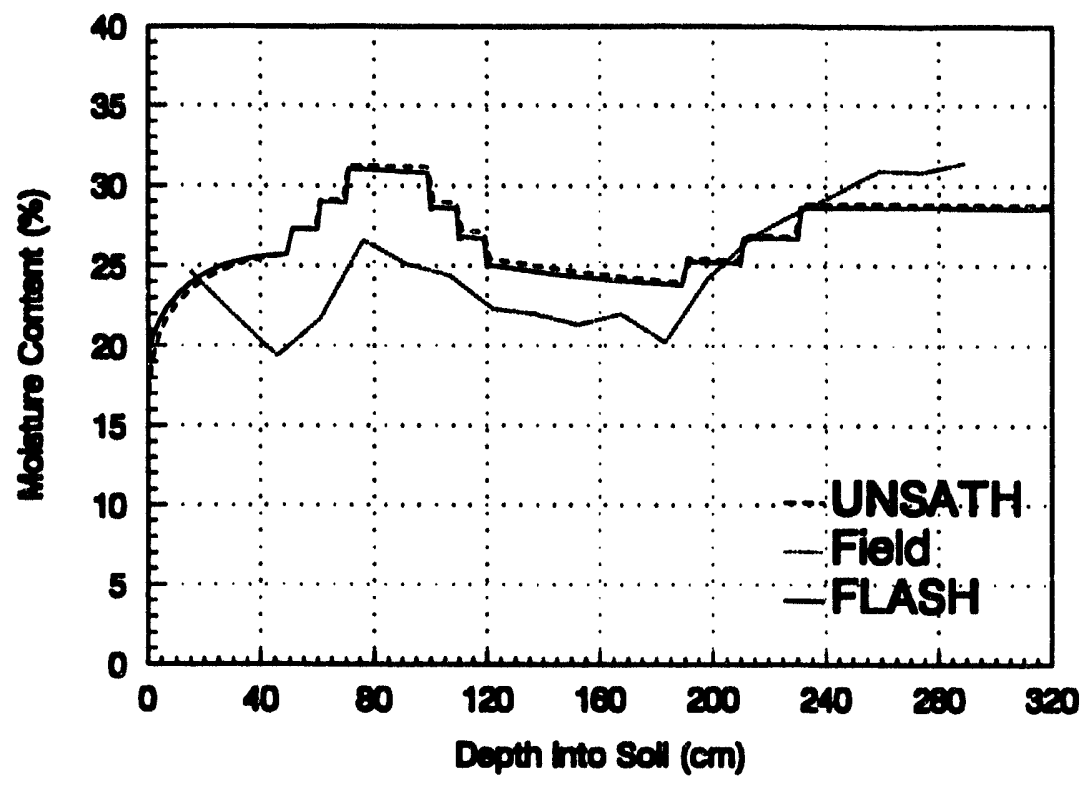

Figure 9. BT-1 soil moisture profile for March 26, 1990.

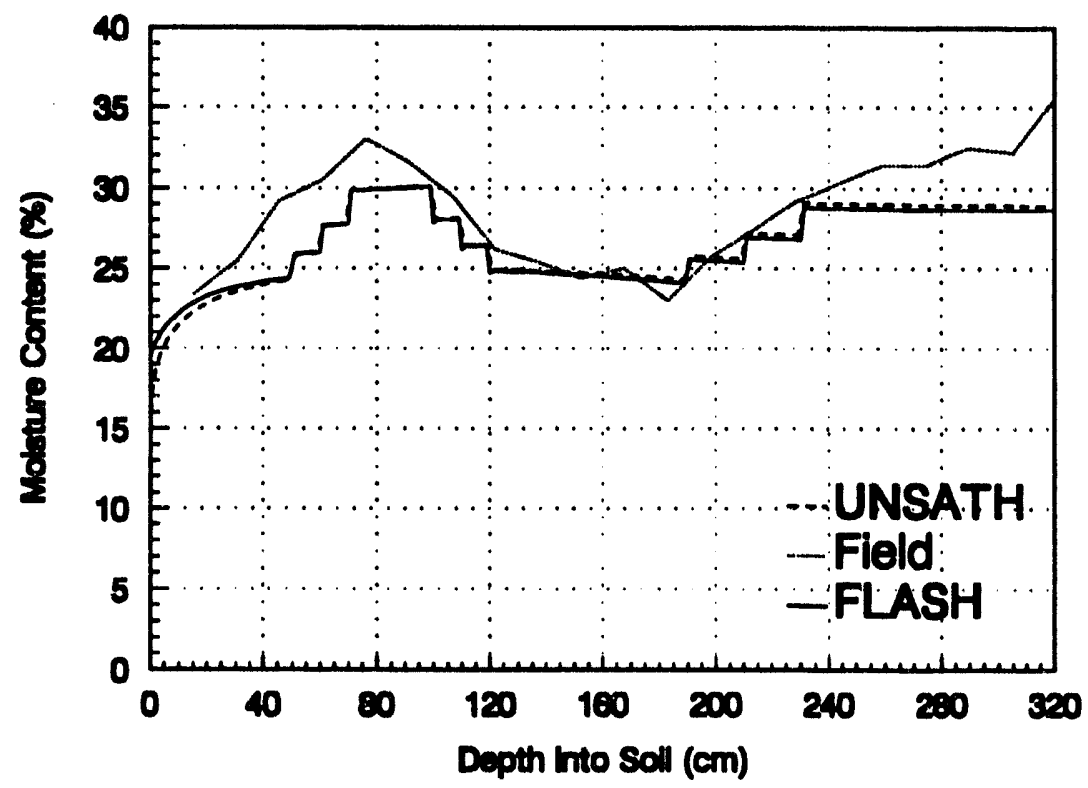

Figure 10. BT-1 soil moisture profile for August 2, 1990. 


\subsection{Transient Free-Surface Flow in Response to Spreading Area Dlecharge}

\subsubsection{Problem Statement for BT-2}

Nearly all of the Snake River Plain Aquifer is unconfined, i.e., the upper surface is able to fluctuate depending on the amount of water entering or leaving the aquifer (Ackerman, 1991). As a result, the elevation of the aquifer surface fluctuates as does the velocity and direction of the water moving through the aquifer. An example of this behavior occurred beneath the RWMC when water infiltrated the aquifer from nearby spreading areas. As a result, the flow directions were rotated as much as 90 degrees (Wood, 1989).

BT-2 was designed to simulate the effect of an influx of water entering the aquifer during the early 1980 s when an above-average amount of precipitation was encountered. During this period, flow from the Big Lost River was diverted from the main channel into spreading areas.

Four spreading areas were constructed near the RWMC to accept access water from the diversion dam on the Big Lost River. The areas were designated A, B, C, and D, and during a flooding event, area $\mathbf{A}$ fills before area $B$, and area $B$ fills before areas $\mathbf{C}$ and $D$ which fill simultaneously (Wood, 1989). Because spreading area B is much more permeable than area $A$ and because areas $C$ and $D$ have rarely filled ${ }^{1}$, it was assumed that all the water diverted from the Big Lost River infiltrates from an area roughly equivalent to spreading area B. A simulation was created in which flow from the Big Lost River enters the Snake River Plain Aquifer from spreading area B during the high water-runoff period, 1982 to 1986 . The simulation was continued for an additional seven years, without the source, to the end of 1993.

\subsubsection{Test Objectives}

This benchmarking problem was designed to demonstrate the ability of the FLASH code to comparably simulate a phreatic water surface and its response to a major flooding event.

\subsubsection{Computer Codes Used}

PORFLOW Version 2.5 was the code used as a benchmark code in this problem because of its ability to simulate a phreatic water surface in two-dimensions.

\footnotetext{
'Private com munication with J.T. Barraclough, 1993.
} 


\subsubsection{Input Specifications}

The model domain was $100 \mathrm{~km}$ by $100 \mathrm{~km}$ with an area of $1.5 \mathrm{~km}$ by $3 \mathrm{~km}$ located in the center of the domain representing spreading area B. The large computational domain was needed so that the solution near the RWMC would not be influenced by the boundary conditions. Water table maps made prior to the construction of the diversion channel were used to estimate a hydraulic gradient of $121.9 \mathrm{~m}$ across $100 \mathrm{~km}$ of the Snake River Plain Aquifer near the RWMC (Mundorf et al., 1964). The gradient was then imposed as specified boundary conditions to simulate the steady-state water table. The upper boundary was set to a total head of $197.92 \mathrm{~m}$ while the lower boundary was set to a head of $76.0 \mathrm{~m}$. The sides parallel to the direction of the flow were assigned as no-flow boundaries.

Field measurements have shown that the Snake River Plain Aquifer in the vicinity of the RWMC has a uniform active flow depth of $76.0 \mathrm{~m}$ and that the flow is produced by differing water table elevations (Mundorf et al., 1964; Robertson et al., 1974). However, because the FLASH code does not permit modeling a phreatic aquifer with varying datum levels, the aquifer depth at one end of the computational domain was assumed to be deeper by the amount of the differing datum levels.

A steady-state simulation was conducted using these boundary conditions to generate initial conditions for the spreading area infiltration simulation. The transient infiltration simulation used flow from the Big Lost River as a volumetric source over spreading area B. A flux of $5.95 \times 10^{6} \mathrm{~m}^{3} / \mathrm{day}$ was applied over the spreading area for the years 1982 to 1986 . The flux was then reduced to $1.32 \times 10^{6}$ $\mathrm{m}^{3} /$ day for the period 1985 to 1986.

Measured hydraulic conductivity and porosity of the aquifer were assigned values $215 \mathrm{~m} /$ day and 0.15, based on aquifer test data from Ackerman (1991). Spacial variation in these parameters was not considered since this was primarily a benchmarking exercise. However, other ongoing studies of the Snake River Plain Aquifer including regions near the RWMC, should use a more detailed description of the hydraulic conductivity and porosity.

The discretized domain for FLASH and PORFLOW is shown in Figure 11. FLASH used 1,638 elements and 5,077 nodes, while PORFLOW was discretized into a grid of $83 \times 87$, for a total of 7,221 nodes. As far as possible, an attempt was made to discretize the domain with the same number and location of nodes in both the FLASH and PORFLOW simulations. However, since FLASH uses an eight-node element and PORFLOW's finite grid yields a nine-node representation of the same domain, the number of nodes in the PORFLOW domain is larger. 


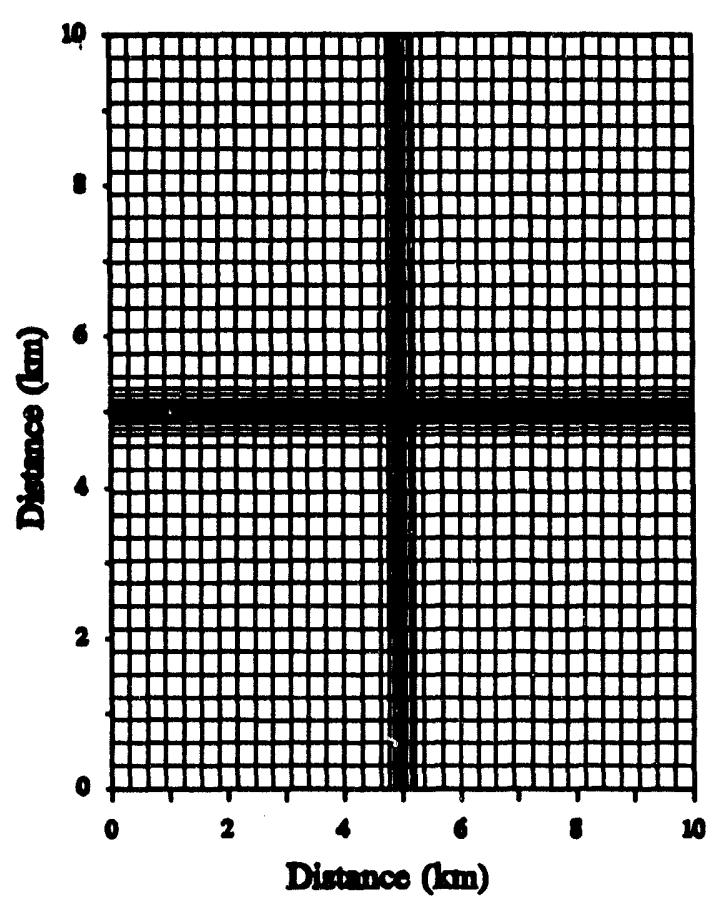

(a)

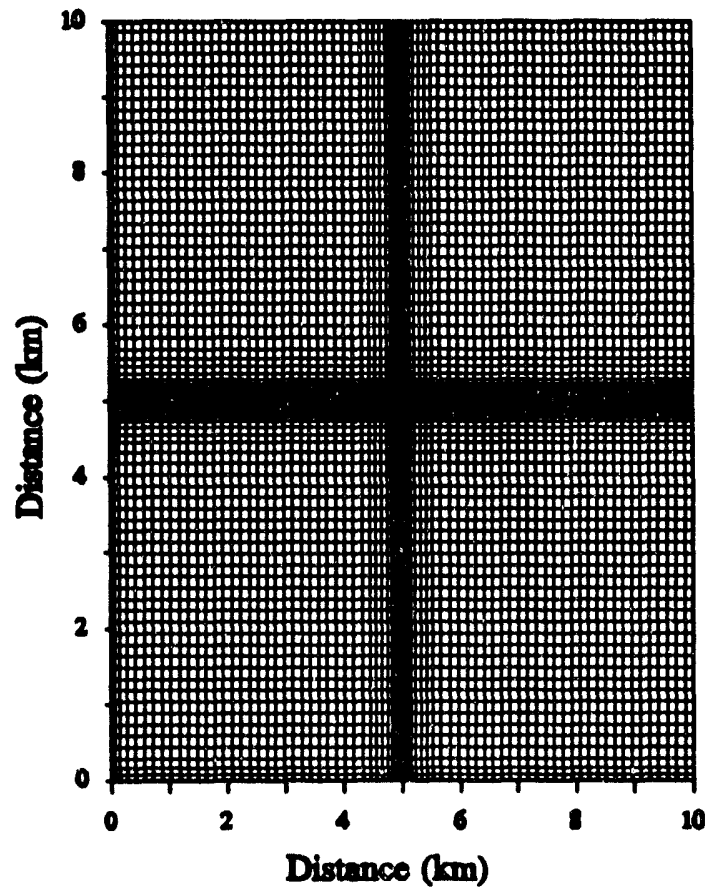

(b)

Figure 11. BT-2 finite element grid for FLASH (a), and finite difference grid for PORFLOW (b). 


\subsubsection{Output Requirements}

The output requirements for BT-2 were contour plots of aquifer depths along with the relative change in aquifer depth due to the influx of water from spreading area $B$. To visualize the change in aquifer depth, the steady-state solution was subtracted from the transient solution at various time planes during the simulation.

\subsubsection{Benchmark Results}

The results of the FLASH and PORFLOW simulations are shown in Figures 12 through 18. As can be seen in Figure 12, the FLASH and PORFLOW steady-state solutions for the initial pressure field agree very well.

However, the increase in aquifer depth due to the source term as predicted by FLASH slightly leads that predicted by PORFLOW throughout the simulation period. By the end of 1984, a $0.5 \mathrm{~m}$ increase in aquifer depth as predicted by FLASH has moved $1,000 \mathrm{~m}$ farther from the source than predicted by PORFLOW. This trend is more dramatic when the rising aquifer level reaches the computational boundaries. Ideally, the rise in aquifer depth should not have reached the no flow boundaries to prevent an artificially high rise due to flow constriction. However, because this was primarily a benchmarking exercise, the condition was permitted. Figure 17 shows a $0.5 \mathrm{~m}$ rise in aquifer depth as predicted by the FLASH code, which again leads the prediction by PORFLOW but the lead has increased to $2,000 \mathrm{~m}$ primarily in the lateral directions.

The maximum increase in aquifer depth was very close as predicted by both codes. The FLASH code predicted a maximum rise of $8.76 \mathrm{~m}$, while PORFLOW predicted a maximum rise of $8.78 \mathrm{~m}$. Contour water table maps produced by Wood (1989) show that the water table rise near USGS well 89 was approximately 5.8 meters. Well 89 is located approximately $3,000 \mathrm{~m}$ north of spreading area $B$. The simulation results produced a water table rise of $6 \mathrm{~m} \mathrm{3,000} \mathrm{m} \mathrm{north} \mathrm{of} \mathrm{the}$ modeled spreading area. This agreement between the simulation results and field measurements was quite good considering the isotropic, homogeneous assumptions for hydraulic properties used in the model.

Figures 17 and 18 show the results at the end of the simulation. Both PORFLOW and FLASH estimated the center of the aquifer rise to travel $10,000 \mathrm{~m}$ down gradient and the pressure field to nearly return to steady state.

Both the FLASH and PORFLOW simulations were performed on a Hewlett Packard 730 workstation. FLASH was extremely slow in comparison to PORFLOW in simulating a free surface 
problem. FLASH took almost 50 times longer to complete the simulation. Run time for FLASH was 6.05 hours while PORFLOW took 7.65 minutes.

The finite element and finite difference methods used in the FLASH and PORFLOW codes produce a large system of algebraic equations, and the different methods used by each code to solve these equations is responsible for the large difference in execution times between the codes. FLASH uses a Gaussian elimination procedure, which requires on the order of $\mathrm{N}^{3}$ operations, where $\mathrm{N}$ is the number of grid nodes. PORFLOW allows the user to choose from several matrix solvers; the Alternating Direction Implicit solver was selected for this problem. The Alternating Direction Implicit solver produces a series of tri-diagonal systems of equations, which may be solved using the Thomas algorithm requiring on the order of only $2 \mathrm{~N}$ operations.

Nonetheless, FLASH shows good overall agreement with PORFLOW, illustrating that the FLASH code successfully solved the free surface transient flow problem.

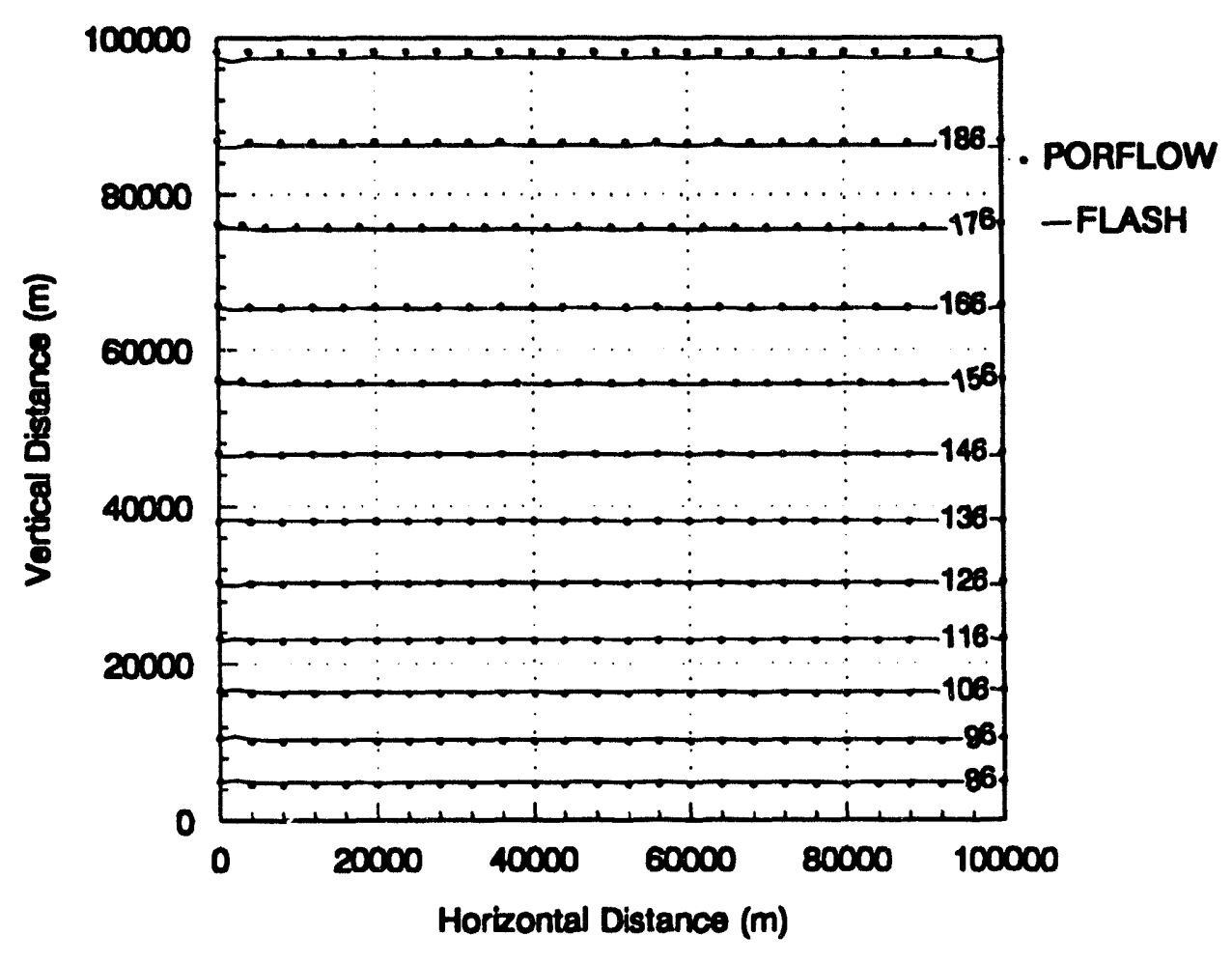

Figure 12. BT-2 initial steady-state pressure field (m). 


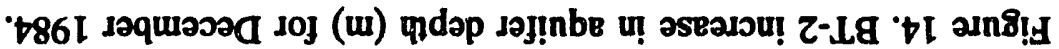

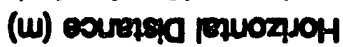

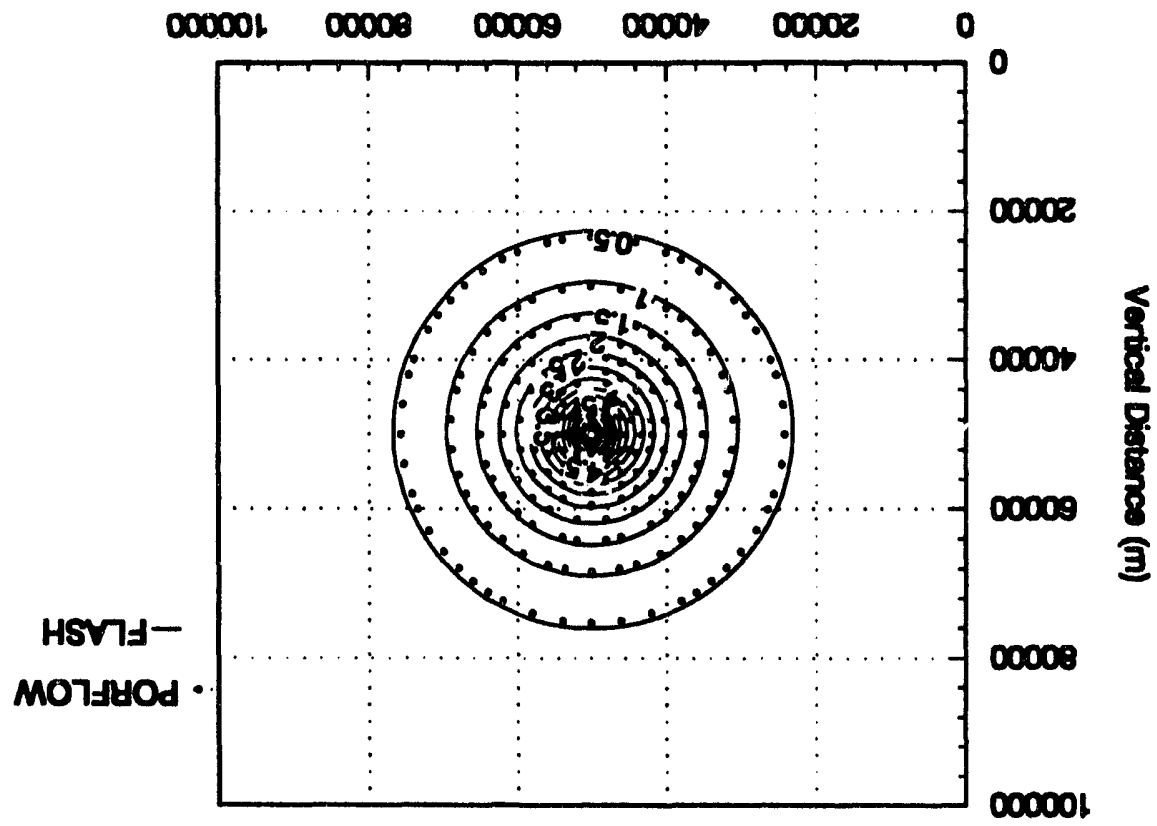

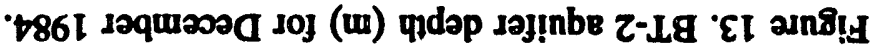

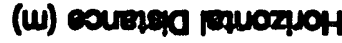

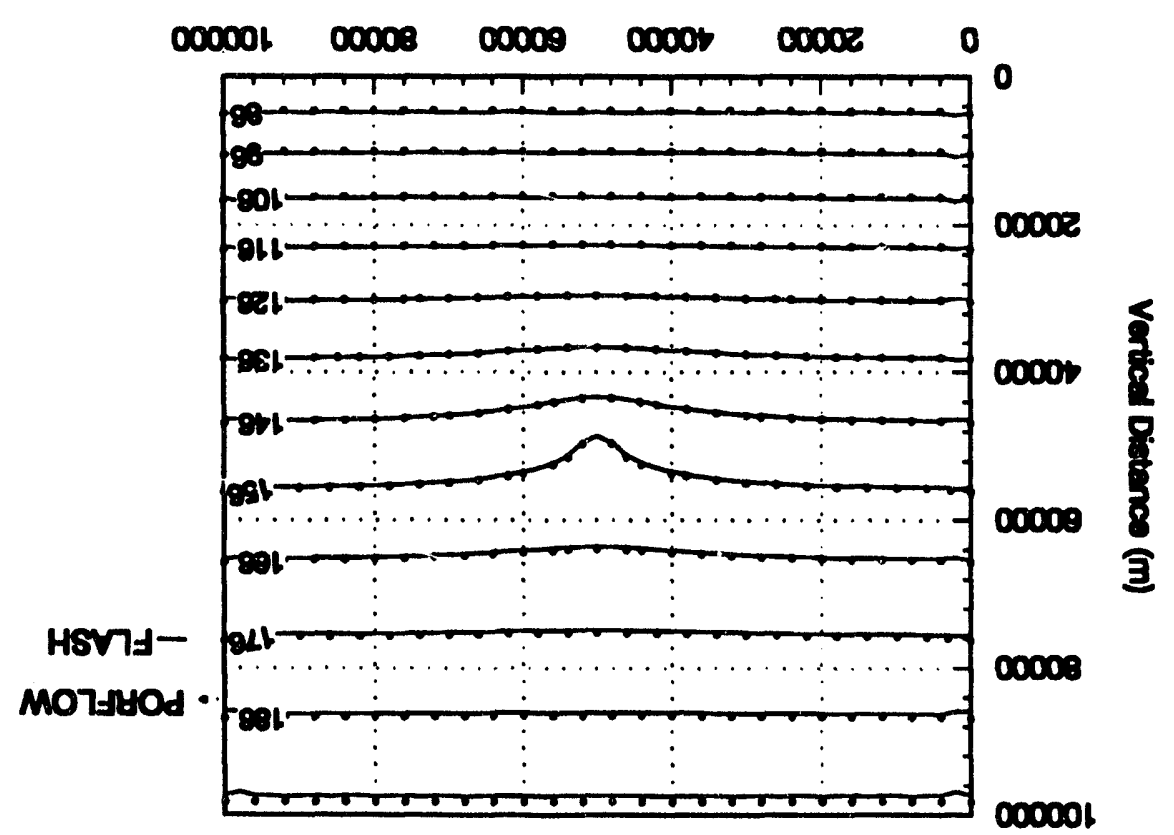




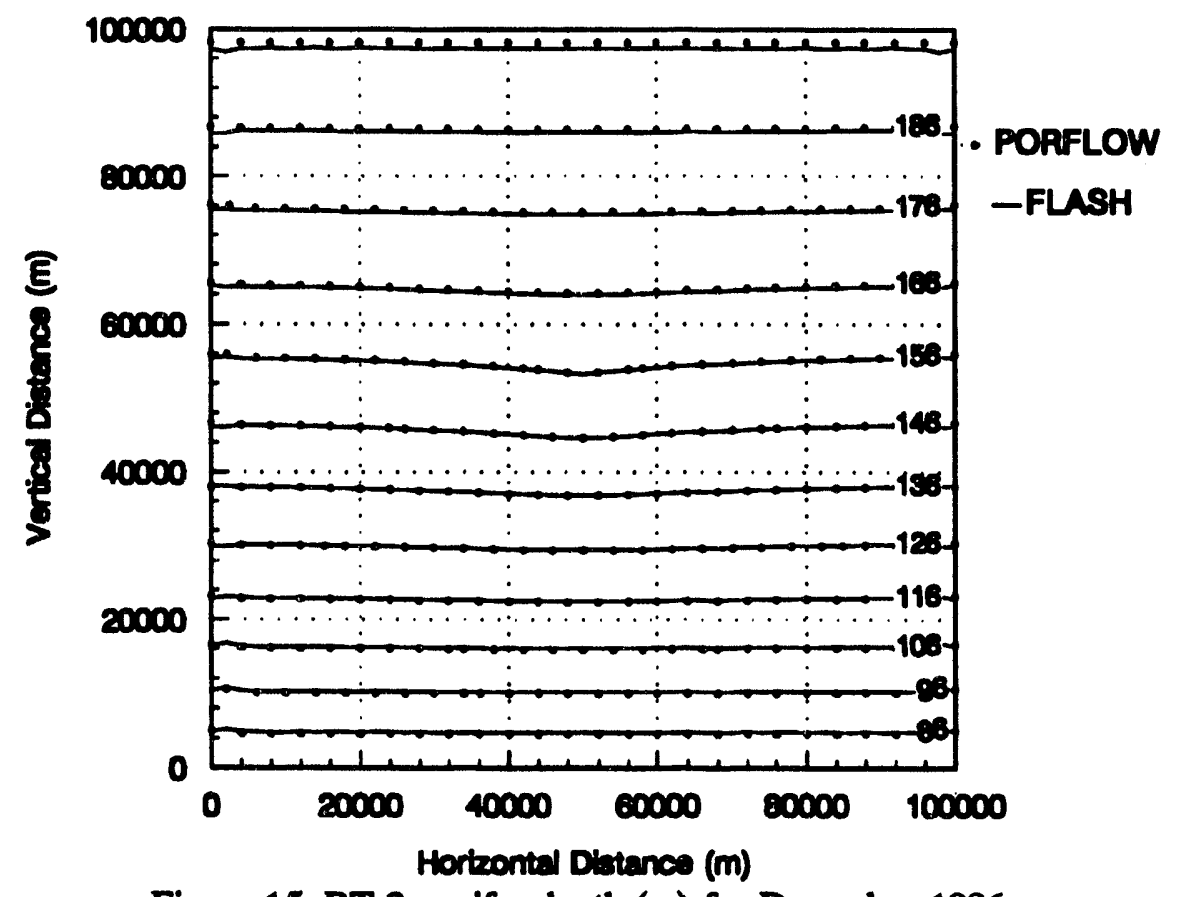

Figure 15. BT-2 aquifer depth (m) for December 1986.

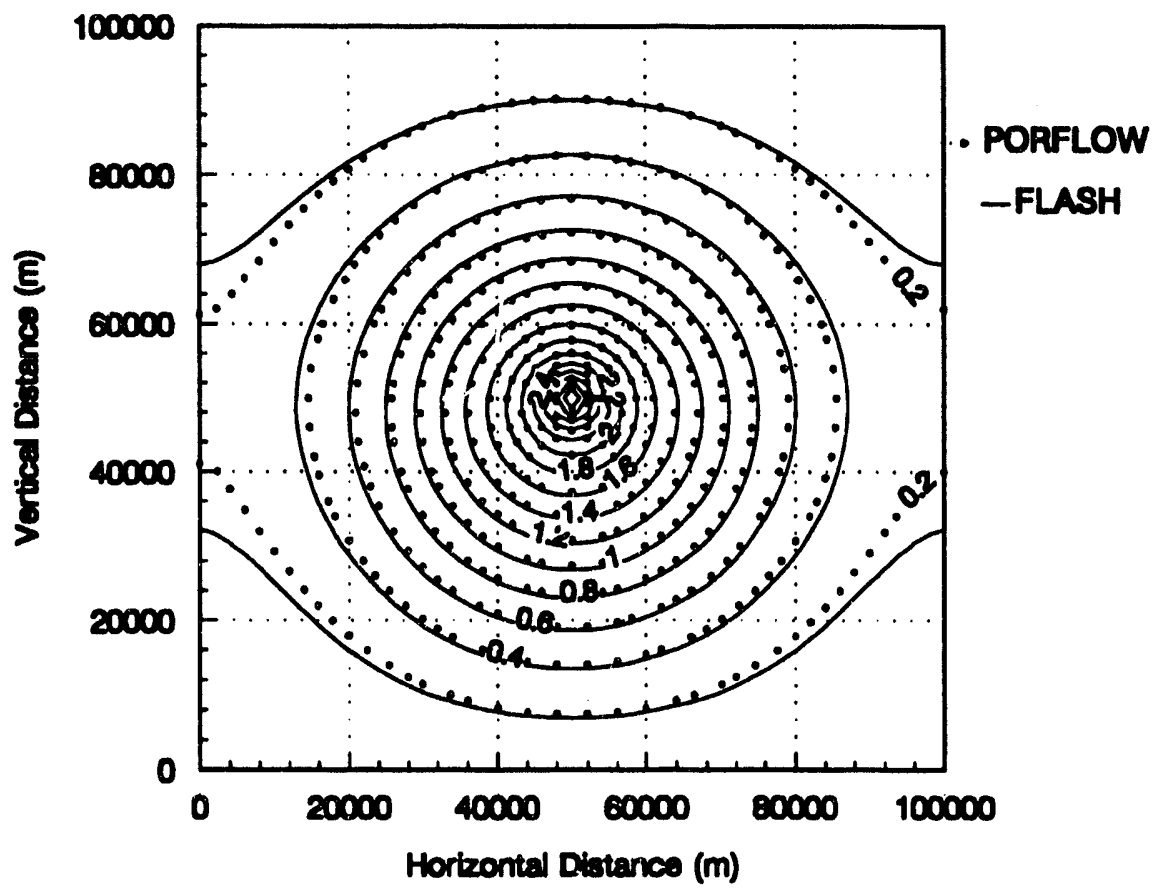

Figure 16. BT-2 increase in aquifer depth $(m)$ for December 1986. 


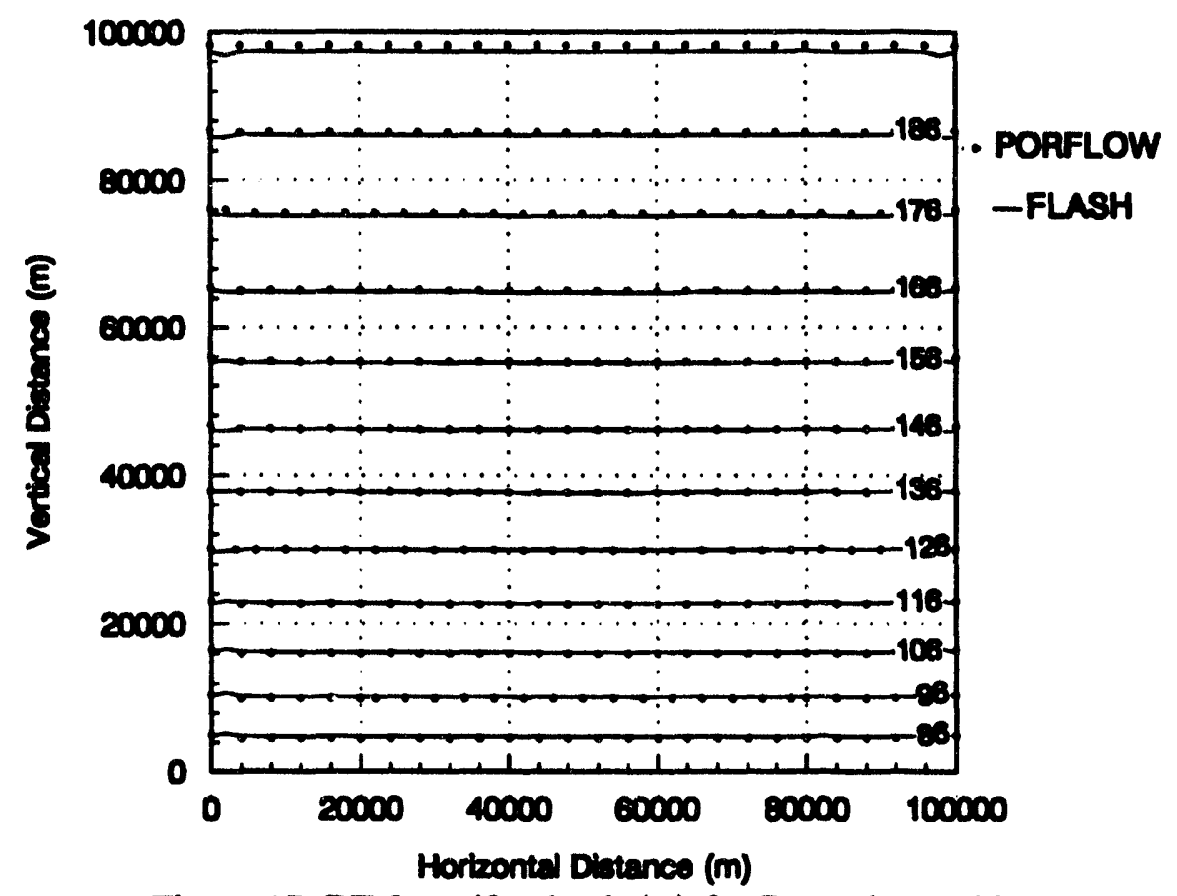

Figure 17. BT-2 aquifer depth (m) for December 1993.

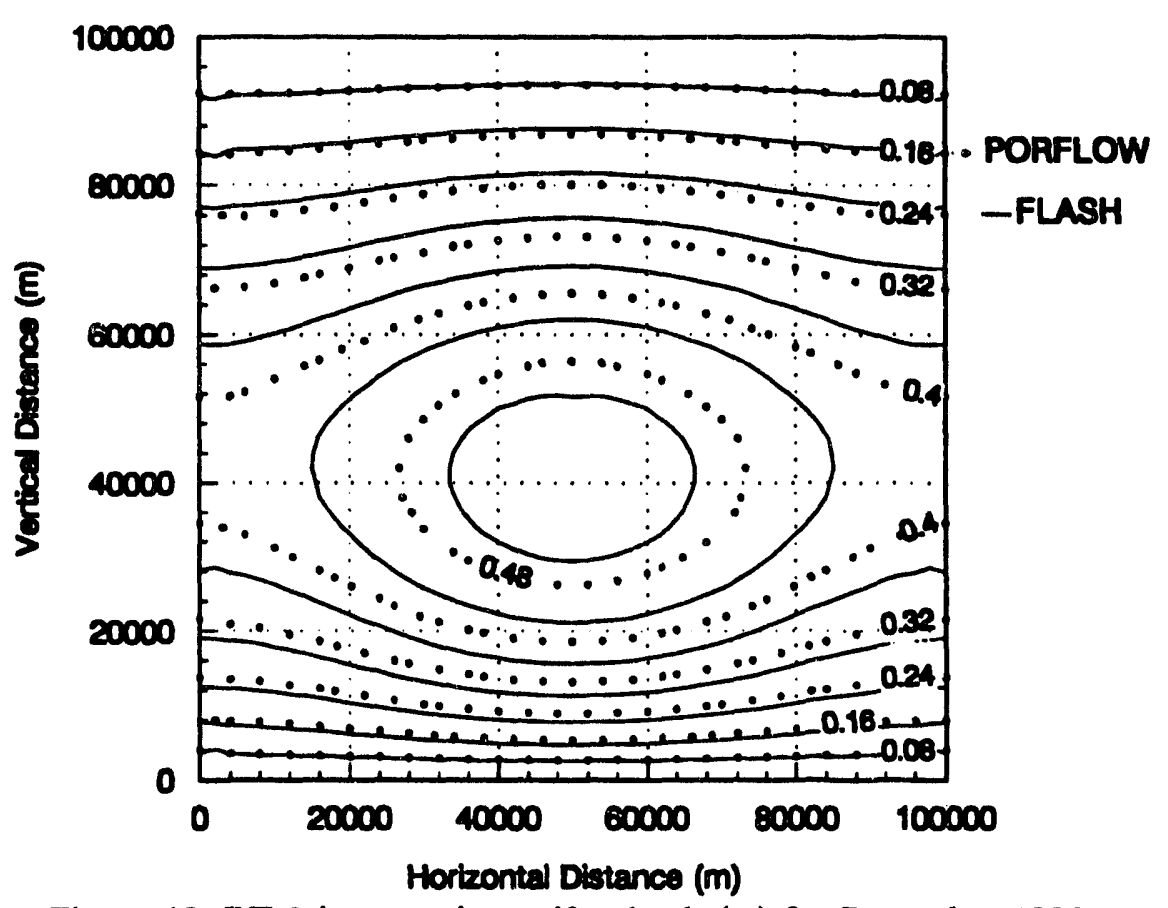

Figure 18. BT-2 increase in aquifer depth (m) for December 1993. 


\subsection{Transient Infiltration from Surface Ditches}

\subsubsection{Problem Statement for BT-3}

The RWMC has a system of drainage ditches designed to carry away surface runoff. This excess runoff normally occurs in the spring during snowmelt. The potential exists for increased subsurface infiltration beneath the ditches due to the surface water being concentrated or focused in the ditches. Increased infiltration could result in a greater likelihood for transport of contaminants down to the underlying Snake River Plain Aquifer. BT-3 was designed to simulate this seasonal infiltration for a 5-year period. The problem was simulated as a two-dimensional vertical half-section to take advantage of symmetry (see Figure 19). Infiltration from a surface ditch was imposed on the left portion of the top boundary by assigning near-saturated conditions for two weeks. During the remainder of the year, background infiltration occurred over the entire top surface.

\subsubsection{Test Objectives}

This benchmarking problem was designed to demonstrate the ability of the FLASH code to comparably simulate a cyclic wetting front advancing through a fractured porous media. The basalt flows beneath the RWMC contain numerous open and infilled fractures. Although the hydraulic properties used to describe the fractures were hypothetical, any future simulations of subsurface movement of water at the RWMC will likely require an ability to include effects of fractures on water movement.

\subsubsection{Computer Codes Used}

Both PORFLOW Version 2.5 and FLASH use a similar method of incorporating fractures into the domain. This method involves superimposing line elements on top of the regular, two-dimensional elements. The codes solve the governing equations for the line elements with the fracture properties rather than the properties of the matrix. Because PORFLOW uses a similar numerical method, it was chosen as a comparison for the FLASH simulation. 


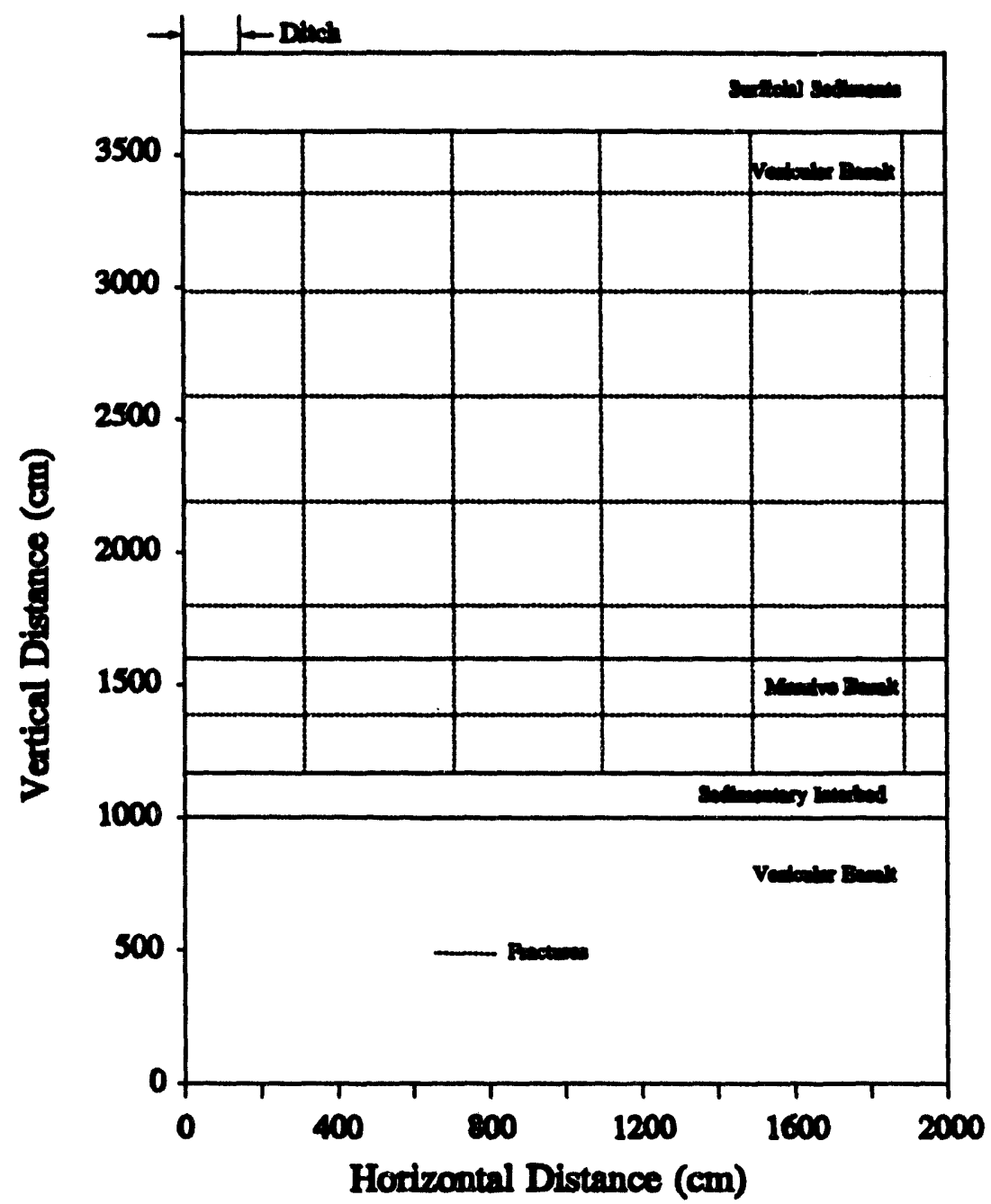

Figure 19. Material type boundaries and fracture locations for BT-3.

\subsubsection{Input Specincations}

The hydraulic properties for each of the materials are given in Table 4. The hydraulic properties of the basalt are from Bishop (1991). Only limited hydraulic data are available for the sedimentary interbed, so the surficial sediments and sedimentary interbeds were assumed to bave the same hydraulic properties. Hydraulic properties for the surficial sediments and the interbed were taken from McElroy and Hubbell (1990). Characterization results from four surficial sediment samples were geometrically averaged. 
Table 4. BT-3 material hydraulic parameters

\begin{tabular}{llllll}
\hline & $\begin{array}{l}\text { Hydraulic } \\
\text { Conductivity } \\
(\mathrm{cm} / \mathrm{s})\end{array}$ & $\begin{array}{llll}\text { Porosity } \\
\end{array}$ & $\begin{array}{l}\text { Residual Moisture } \\
\text { Content } \\
\end{array}$ & $\begin{array}{lll}\theta_{\mathrm{r}} \\
(1 / \mathrm{cm})\end{array}$ & a \\
\hline Sediments & $7.59 \times 10^{-5}$ & 0.48 & 0.1 & 0.012 & 1.36 \\
Massive Basalt & $1.00 \times 10^{-4}$ & 0.15 & 0.01 & 0.038 & 1.47 \\
Vesicular Basalt & $1.16 \times 10^{-5}$ & 0.23 & 0.015 & 0.038 & 1.47 \\
Massive Basalt Fractures & $7.59 \times 10^{-5}$ & 0.48 & 0.1 & 0.012 & 1.36 \\
Vesicular Basalt Fractures & $9.80 \times 10^{-2}$ & 0.50 & 0.005 & 0.03 & 2.43 \\
\hline
\end{tabular}

Separate hydraulic properties were used for the vesicular and massive basalt fractures because cores of the massive basalt fractures have shown more infilling than those of the vesicular basalt. All of the properties for the vesicular fractures were arbitrarily assigned based upon the fracture aperture of $0.5 \mathrm{~cm}$. The moisture characteristic curve for the vesicular basalt fractures was taken from Wösten and Van Genuchten (1988). Since sediment infilling has been observed in fractures in the massive basalt, the hydraulic properties were assigned to be the same as the sediments.

Figure 19. shows the domain for the RWMC ditch and the soil type boundaries along with fracture locations. Based on information from Knutson et al. (1992), a 4-m fracture spacing was assigned in both the vertical and horizontal directions. The discretized domain for FLASH, shown in Figure 20, used 3,570 elements and 9,528 nodes, while PORFLOW was discretized into a grid of $53 \times$ 213, for a total of 11,289 nodes. Line elements do not appear in Figure 20 because they overlap element boundaries. An attempt was made to discretize the domain with the same number and location of nodes in both the FLASH and PORFLOW simulations. However, since FLASH uses an eight-node element and PORFLOW's finite grid yields a nine-node representation of the same domain, the number of nodes in the PORFLOW domain is larger. Additionally, in the area below the ditch, FLASH required additional grid refinement in the order to simulate the higher flux of water during flooding (see Figure 20).

The boundary going down the left side of the simulation domain is treated as a no-flux boundary because of symmetry since the boundary is at the center of the ditch. The boundary on the right side is also treated as no-flux since it is located far enough away from the ditch so that all water 
movement is strictly vertical. In order to simulate the infiltration events, a time-varying upper boundary condition had to be used. During these events, the upper boundary was fixed over the portion representing the ditch to a pressure of $-1 \mathrm{~cm}$, and the rest of the upper boundary was assigned background infiltration of $5 \mathrm{~cm} / \mathrm{yr}$. The lower boundary was fixed at a pressure of $\mathbf{- 3 0} \mathrm{cm}$; this corresponds to unit gradient conditions at the background infiltration rate. At the conclusion of the spring snowmelt, the entire upper boundary was set to constant flux of $5 \mathrm{~cm} / \mathrm{yr}$ for the remaining 50 weeks. The initial conditions at the beginning of the first infiltration event used a steady-state flow field from a background infiltration rate of $5 \mathrm{~cm} / \mathrm{yr}$ as initial conditions. This cycle of snowmelt and background infiltration was simulated for a total of 5 years.

\subsubsection{Output Requirements}

Because the results of the pressure fields were complex, a graphical comparison was necessary to interpret the results. Two separate contouring methods were used to compare results. The first method was contouring the pressure field. The second was to subtract the initial steady-state solution from each time plane in order to plot the advance of the moisture front. 


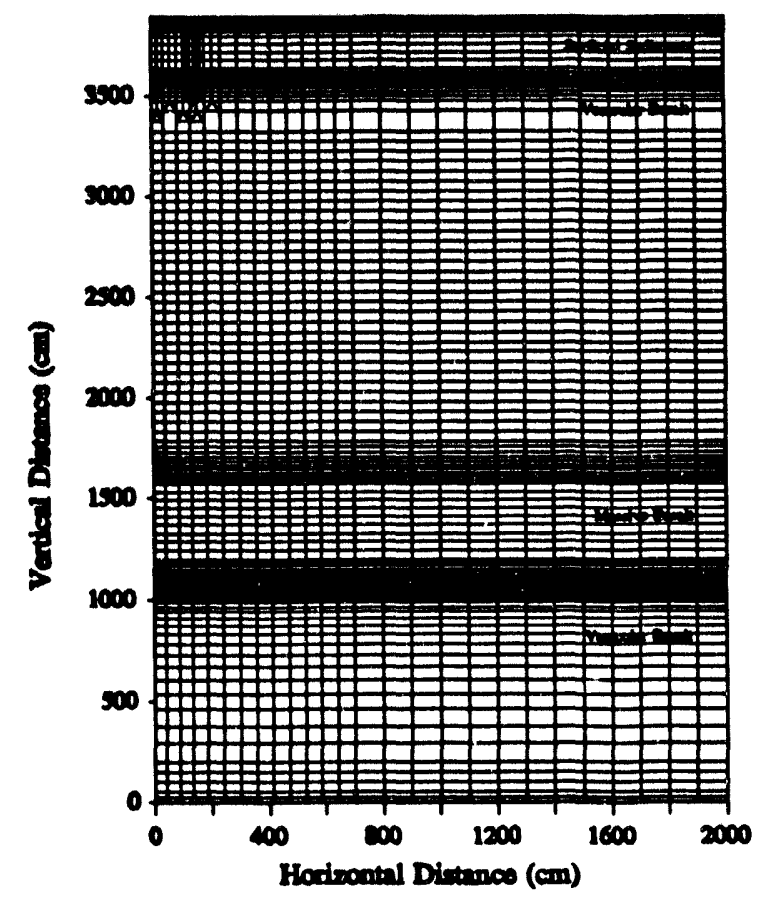

(a)

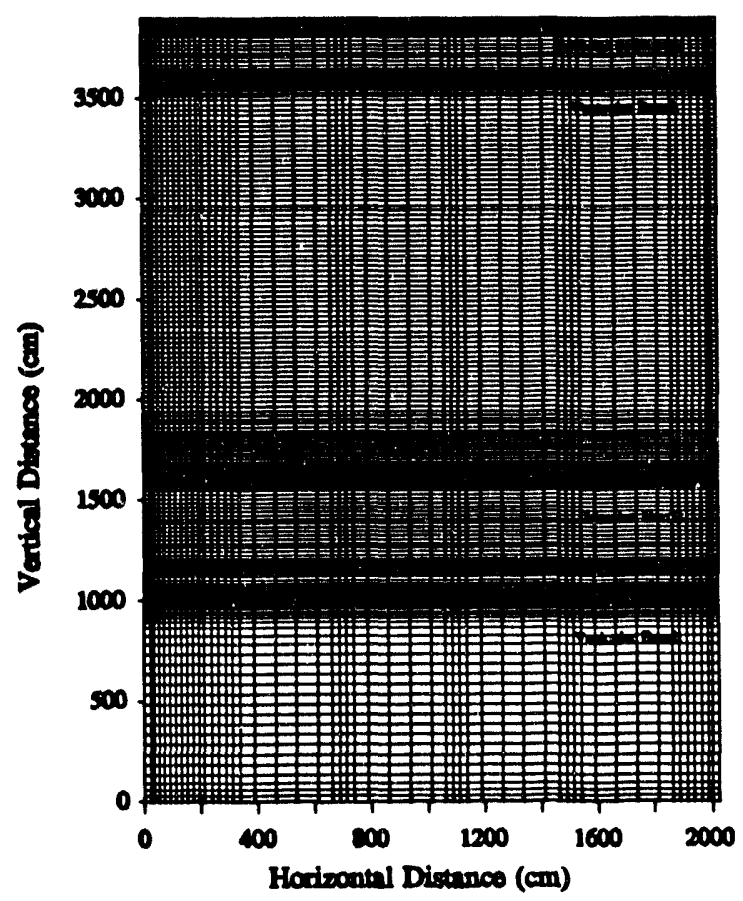

(b)

Figure 20. BT-3 finite element grid for FLASH (a), and finite difference grid for PORFLOW (b). 30 


\subsubsection{Benchmark Results}

Figure 21 illustrates the reduction in pressure bead due to the advancing wetting front after the third infiltration event. Although the FLASH results lead those from PORFLOW, the general pattern is consistent with PORFLOW. However, by the end of the simulation (Figure 22), the wetting front from PORFLOW has caught up to that of FLASH. While there is not excellent agreement eariy in time, Figure 22 shows that both numerical codes place the advancing front at approximately the same location by the end of the simulation. Both FLASH and PORFLOW show the front reaching the sedimentary interbed and then spreading borizontally. Additionally, both Figures 21 and 22 indicate consistent horizontal spreading within the massive basalt, which shows the influence of a horizontal fracture. If contaminants had been present in the massive basalt region, they would have had their plumes spread farther by these pulses of water. Figure $\mathbf{2} 3$ shows that the pressure fields at the end of the simulation are in excellent agreement. While fractures appear to have a significant role in moving the wetting front vertically away from the source, they do not appear to be the dominant mechanism of horizontal movement of the wetting front. Rather, the nonfractured sedimentary interbed causes the majority of horizontal movement.

Two problems were encountered during the FLASH simulation. The first involved a lack of flexibility in FLASH in assigning the upper boundary conditions. A preferred way of assigning the upper boundary conditions would have been to change the infiltration rate over the ditch to represent water present in the ditch. The FLASH code allowed only one infiltration rate to be assigned at any one time, and this was used for the background infiltration rate. For this reason, first-type boundary conditions were used for the ditch. Since the background infiltration rate had to be used over the portion of the upper boundary away from the ditch, it was necessary to increase the horizontal discretization at the boundary between the ditch and the remainder of the upper portion of the simulation domain in order for FLASH to handle this juxtaposition in the boundary conditions.

The second problem that arose in the FLASH simulation was when a first-type boundary condition of $0 \mathrm{~cm}$ was assigned for the ditch. FLASH did not handle the advancing wetting front resulting from the $0 \mathrm{~cm}$ boundary condition and kept cutting the time step. When the first-type boundary was changed to $-1 \mathrm{~cm}$, FLASH was very successful. Discussions with the principal author of FLASH regarding this problem may result in improvements in the code. For the time being, applications of the FLASH must be limited to problems in which complete saturation (i.e., perched water) do not occur.

FLASH was very efficient with computational resources in comparison to PORFLOW. By 
using the modified Picard solver with linear basts functions, FLASH was able to complete the suite of runs in less than half of the time of PORFLOW. Run time for FLASH was 2.58 hours while PORFLOW took 7.76 hours. 


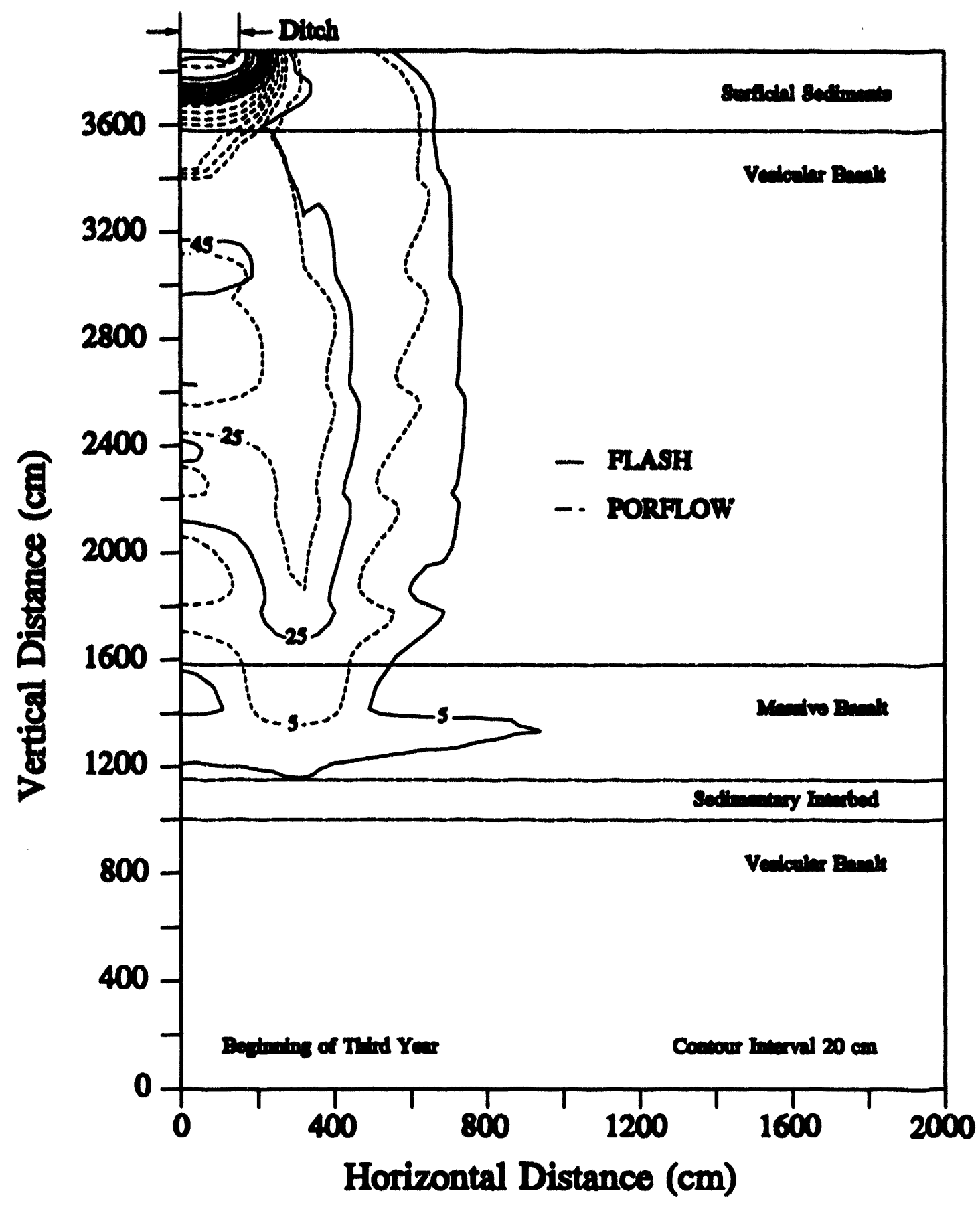

Figure 21. BT-3 decrease in pressure from wetting front advance at the beginning of the thind year. 


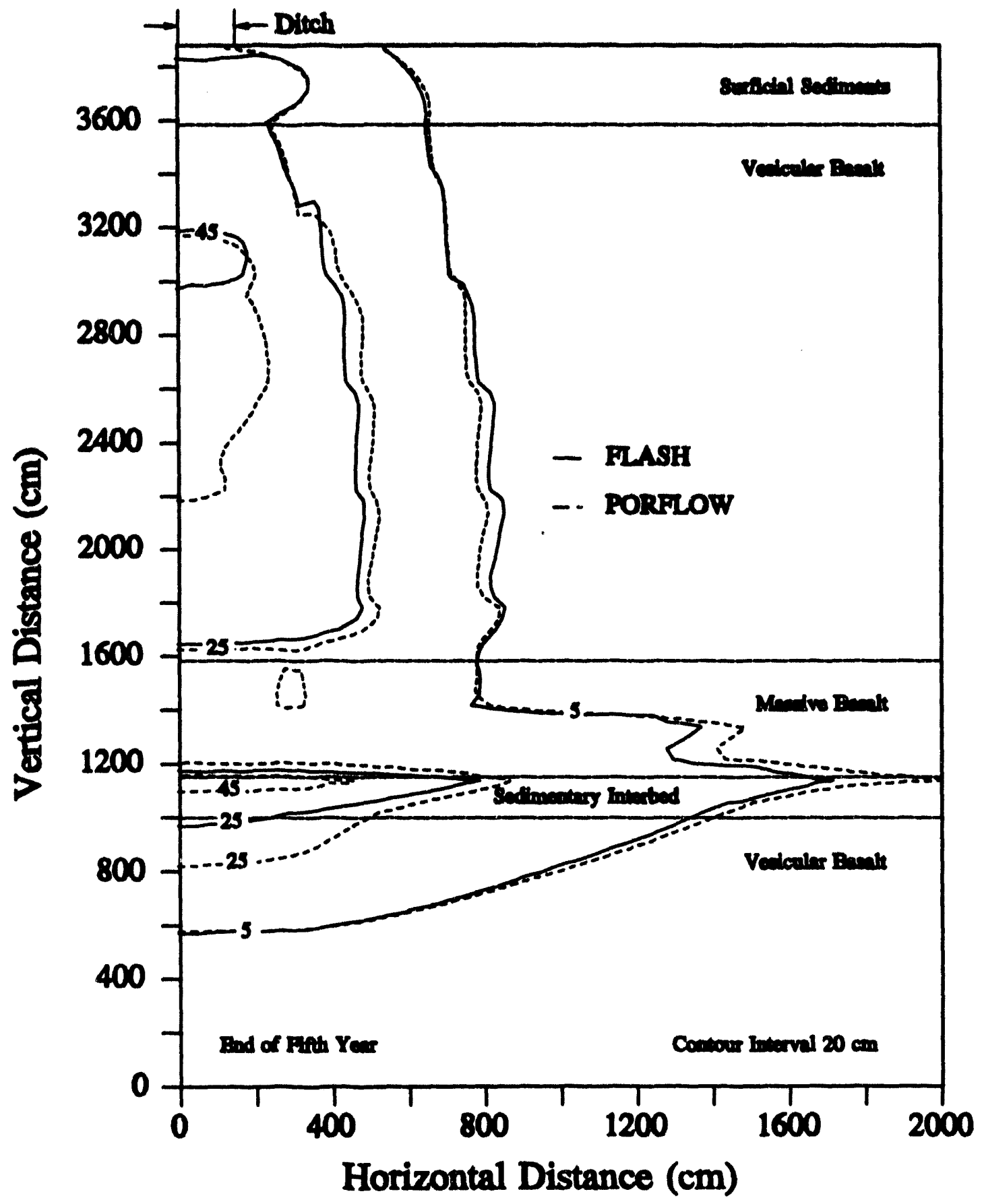

Figure 22. BT-3 decrease in pressure bead from wetting front advance at the end of the fifth year. 


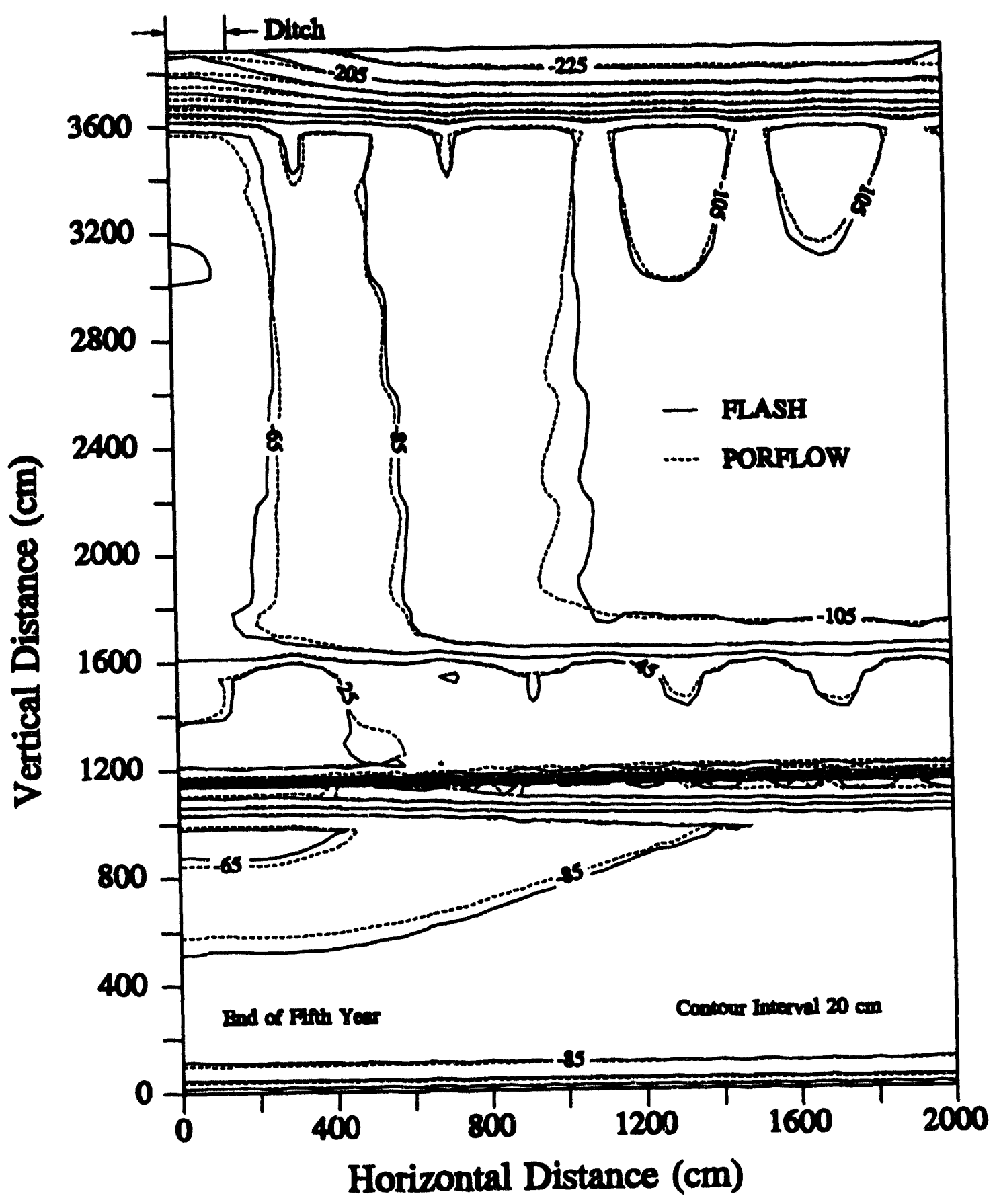

Figure 23. BT-3 pressure fields at the end of simulation. 


\subsection{FINDINGS AND RECOMMENDATIONS}

Benchmark testing of the FLASH computer code was conducted to determine if the code is ready for use in performance assessments studies of the Radioactive Waste Management Complex. The testing was designed to check the computational efficiency, accuracy of the numerical algorithms, and the capability of the code to simulate diverse hydrological conditions.

This testing was performed on a qualitative basis using graphical comparisons of the numerical solutions. The primary findings and recommendations obtained from this testing are summarized bere.

\subsection{General Findings}

Results of the three benchmark test cases showed good agreement between the FLASH simulations and those of the benchmark codes. The results also demonstrated good stability with acceptable computational efficiency while simulating a wide range of conditions. Although, FLASH ran test case BT-1 faster than UNSAT-H and test case BT-3 faster than PORFLOW, test case BT-2 illustrated FLASH was much slower than PORFLOW while executing a saturated simulation. The large difference in execution times between FLASH and PORFLOW indicate there may be some room for improving the computational efficiency of the FLASH code, particularly for saturated simulations.

The code documentation was found to be inadequate, primarily the input guide section. In order to determine the correct keywords and input sequence, the authors found it necessary to examine the FORTRAN source coding. In general, FLASH was easy to setup and run once the keyword input scheme was fully understood.

Based on the overall results of the benchmark testing, it was concluded that FLASH is a versatile tool for analysis of saturated, confined or unconfined aquifers and unsaturated flow patterns provided moisture contents do not reach saturation.

Because of problems identified by test case BT-3, namely a failure of the code to converge during a unsaturated to saturated transition, the current version of FLASH appears to be only partially operational. Consequently, the code should not be used when this condition occurs or is expected to occur, i.e. when perched water is present or when infiltration rates exceed the saturated conductivity of the soil. This fault in the FLASH code severely limits the usefulness of the code as most realistic simulations of the vadose zone encounter a near saturated condition at one time or another. 


\subsection{Recommended Refinements}

The FLASH computer code Version 3.0 represents a high level of code development. However, the benchmark testing reported here has identified the following areas which need improvement in succeeding versions:

- Computational algorithms

- Input and output options

- Code documentation.

Specific recommendations for improvements in these areas are discussed below.

\subsubsection{Computational Algorithms}

The FLASH code's failure to converge at the unsaturated to saturated transition is most likely due to two problems. As the matric potentials approach zero, the system of algebraic equations generated by the finite element method can (1) become ill conditioned, i.e. small changes in the matrix result in large changes in the solution, or (2) the system of equations becomes increasingly singular, i.e. more than one solution exists for the system. An ill conditioned system would occur when small changes in matrices $A$ or $B$, in the equation $A x=B$ result in large changes in the solution matrix $x$. $A$ system would become increasingly singular as matrix $B$ in the equation approaches zero. Both problems indicate a more sophisticated matrix solver is needed.

These problems are further multiplied when very large systems are solved. Accumulated roundoff errors due to machine precision limits can further push large systems towards being ill conditioned or singular. When using direct matrix solvers such as Gaussian elimination, practical upper limits on the order of linear systems being solved using smaller machines may be of the size 100 to 500 (Atkinson, 1988). Implementation of double precision into the FLASH code as well as adding an indirect matrix solver such as a conjugate gradient solver could improve stability at the saturated to unsaturated transition as well as increase computational efficiency. Discussions with the principal author of the FLASH code indicated a matric solver package is being added which will allow code users to select several matric solvers including a conjugate gradient method.

Solving the system of algebraic equations constitutes a large fraction of total computational time used during a simulation. Gaussian elimination can be relatively slow and use a large amount of storage space compared to indirect methods such as a conjugate gradient method. This is especially true for the sparse banded matrices produced by the finite element method. Additionally, if a good estimation of solution is available, i.e. a good estimate of initial conditions which change slowly, the 
indirect methods will greatly outperform the direct methods.

The automatic time step algorithm which either halves or doubles the time step in accordance with solution parameters such as maximum and minimum changes in state variables and the number of iterations worked well and was appreciated by the tester. Nonetheless, test case BT-1 showed the algorithm would increase the time step beyond individual periods of infiltration and the code would not see the infiltration applied during the short period. This problem could easily be fixed by adding an option to limit the maximum time step size during specific time periods.

\subsubsection{Input and Output}

The narrative style command sequence used in the input file for the FLASH code was user friendly and appeared to work well, but some refinement could be employed. The narrative style input used special keywords to control the simulation as well as describe the input of model parameters. However, if a user inadvertently used a keyword in a comment lines, the keyword could be read as a control variable. Preventing the code from inadvertently reading any keywords in comment lines as well as eliminating the use of keywords in comment lines would greatly decrease the possibility of input errors.

\subsubsection{Code Documentation}

The input guide section of the FLASH documentation (Baca and Magnuson, 1992) only provides a superficial description of the keywords and keyword syntax. A more comprehensive input section is needed. Additionally, two instances were discovered when keywords were incorrect or confusing. Specific changes to the input section or conversely to the FORTRAN source code that should be made are

(1) The unit gradient comment line must contain the keywords Bottom Flux instead of Unit Gradient.

(2) The specific storage variable input under the Properties keyword is used as the specific yield when the Dupuit-Forcheimer equation is solved i.e., in unconfined aquifer simulations.

(3) Attention should be called to the point that use of the keyword linear invokes the use of linear shape functions i.e., state variables at element middle nodes are not directly solved for but are linearly interpolated from end node values.

Finally, a list of variable definitions used in the FORTRAN coding should be included in the 
code documentation as an separate section or an appendix. A comprehensive list of variables would allow easier debugging and/or tracing input errors by the code users.

\subsection{Recommendations for Additional Testing}

The various benchmark $t$ cases were aimed at testing the major features of the FLASH code, namely saturated and unsaturated fluid flow. However, the heat transport option was not tested due to time constraints. Simulating heat transport in soil can be important because many physical and chemical properties of contaminants are affected by soil temperatures. 


\subsection{REFERENCES}

Ackerman, D.J., 1991, Transmissivity of the Snake River Plain Aquifer at the Idaho National Engineering Laboratory, Idaho, U.S. Geological Survey Water Resources Investigations Report 914058.

Atkinson, K.E., 1988, An Introduction to Numerical Analysis, John Wiley \& Sons, Inc., New York, NY.

Baca, R.G. and S.O. Magnuson, 1992, FLASH - A Finite Element Computer Code for Variably Saturated Flow, EGG-GEO 10274, EG\&G Idaho Inc., Idaho Falls, ID.

Bishop, C.W., 1990, "Hydraulic Properties of Vesicular Basalt", M.S. Thesis, University of Arizona.

Case, M.J., S.J. Maheras, M.A. Mckenzie-Carter, M.E. Sussman, and P. Voilleque, 1990, Draft Radioactive Waste Management Complex Performance Assessment, EGG-WM-8773, EG\&G Idaho Inc., Idaho Falls, ID.

Crichlow, H.B., 1977, Modern Reservoir Engineering, Prentice-Hall, Englewood Cliffs, NJ (1977).

Fayer, M.J., G.W. Gee, and T.L. Jones, 1986, UNSAT-H Version 1.0: Unsaturated Flow Code Documentation and Applications for the Hanford Site, PNL-5899, Pacific Northwest Laboratory, Richland, WA.

Knutson, C.F, K.A. McCormick, J.C. Crocker, M.A. Glenn, and M.L. Fishel, 1992, 3D RWMC Vadose Zone Modeling (Including FY-89 to FY-90 Basalt Characterization Results, EGG-ERD-10246, EG\&G Idaho, Inc., Idaho Falls, ID.

Magnuson, S.O., R.G. Baca and A.J. Sondrup, 1990, Indepedent Verification and Benchmark Testing of the PORFLO-3 Computer Code, Version 1.0, EGG-BG-9175, EG\&G Idaho Inc., Idaho Falls, ID. 
Magnuson, S.O., 1993, A Simulation Study of Moisture Movement in Proposed Barriers for the Subsurface Disposal Area, Idaho National Engineering Laboratory, EGG-WM-10974, EG\&G Idaho Inc., Idaho Falls, ID.

Martian, P. and J.N. Chung, 1992, Independent Verification and Validation Testing of the FLASH Computer Code, Version 3.0, EGG-GEO-10330, EG\&G Idaho Inc., Idaho Falls, ID.

McElroy, D.L. and J. Hubbell, 1990, Hydrologic and Physical Properties of Sediments at the Radioactive Waste Management Complex, EGG-BG-9147, p. A-219.

McElroy, D.L., 1990, Vadose Zone Monitoring at the Radioactive Waste Management Complex at the Idaho National Engineering Laboratory 1985-1989, EGG-WM-9299, EG\&G Idaho, Inc., Idaho Falls, ID.

Mundorf, M.J., Crosthwaite, E.G., and Kilburn, Chabot, 1964, Groundwater for Irrigation in the Snake River Basin in Idaho, U.S. Geological Survey Water-Supply Paper 1654, plate 4.

Pantankar, S.V., 1980, Numerical Heat Transfer and Fluid Flow, Hemisphere Publishing Corporation, New York, NY.

Richardsn, C.W., and D.A. Wright, 1984, WGEN: A Model for Generating Daily Weather Variables, United States Department of Agriculture (Agriculture Research Service), USDA Report PB85-107100.

Robertson, J.B., R. Schoen, J.T. Barraclough, 1974, The Influence of Liquid Waste Disposal on the Geochemistry of Water at the National Reactor Testing Station, Idaho: 1952-1970, U.S. Geological Survey Open-File Report, IDO-22053.

Runchal, A.K. and B. Sagar, 1993, PORFLOW: A Model for Fluid Flow, Heat and Mass Transport in Multifluid, Multiphase Fractured Porous Media: User's Manual - Version 2.50, Analytic and Computational Research, Inc., Los Angeles, CA. 
Schnabel, R.R. and E.B. Richie, 1984, "Calculation of Intemodal Conductances for Unsaturated Flow Simulations: A Comparison", Soil Science Society American Joumal, 48, 1006-1010.

Wood, T.L., 1989, Preliminary Assessment of the Hydrogeology at the Radioactive Waste Management Complex, Idaho National Engineering Laboratory, EGG-WM-8694, EG\&G Idaho, Inc., Idaho Falls, ID.

Van Genuchten, M.T., 1980, "A Closed-Form Equation for Predicting the Hydraulic Conductivity of Unsaturated Soils", Soil Science Society of America Joumal, 44, pp. 892-898.

Wösten, J.H.M., and M.Th. Van Genuchten, 1988, "Using Texture and Other Soil Properties to Predict the Unsaturated Soil Hydraulic Functions, Soil Science American Journal, 52, pp. 1762-1770. 
APPENDIX A - SAMPLE INPUT FILES FOR BENCHMARK PROBLEM

A-1 
This appendix presents condensed versions of the input decks used in the benchmarking of the FLASH computer code. Some parts of the input decks have been omitted because of their length and redundancy. Additionally, many of the FLASH simulations required several runs in which source terms were turned on or off, and only the first input deck is included because of the similarity between runs. The presented card decks include only the minimal information required to duplicate the simulations. To rerun the FLASH benchmark tests, the user must reconstruct the omitted lines from the information presented in the input specification sections of this report and obtain the geometry files .igi) and initial condition files (".ici) for the FLASH simulations as well as the meteorological data for BT-1 from the authors.

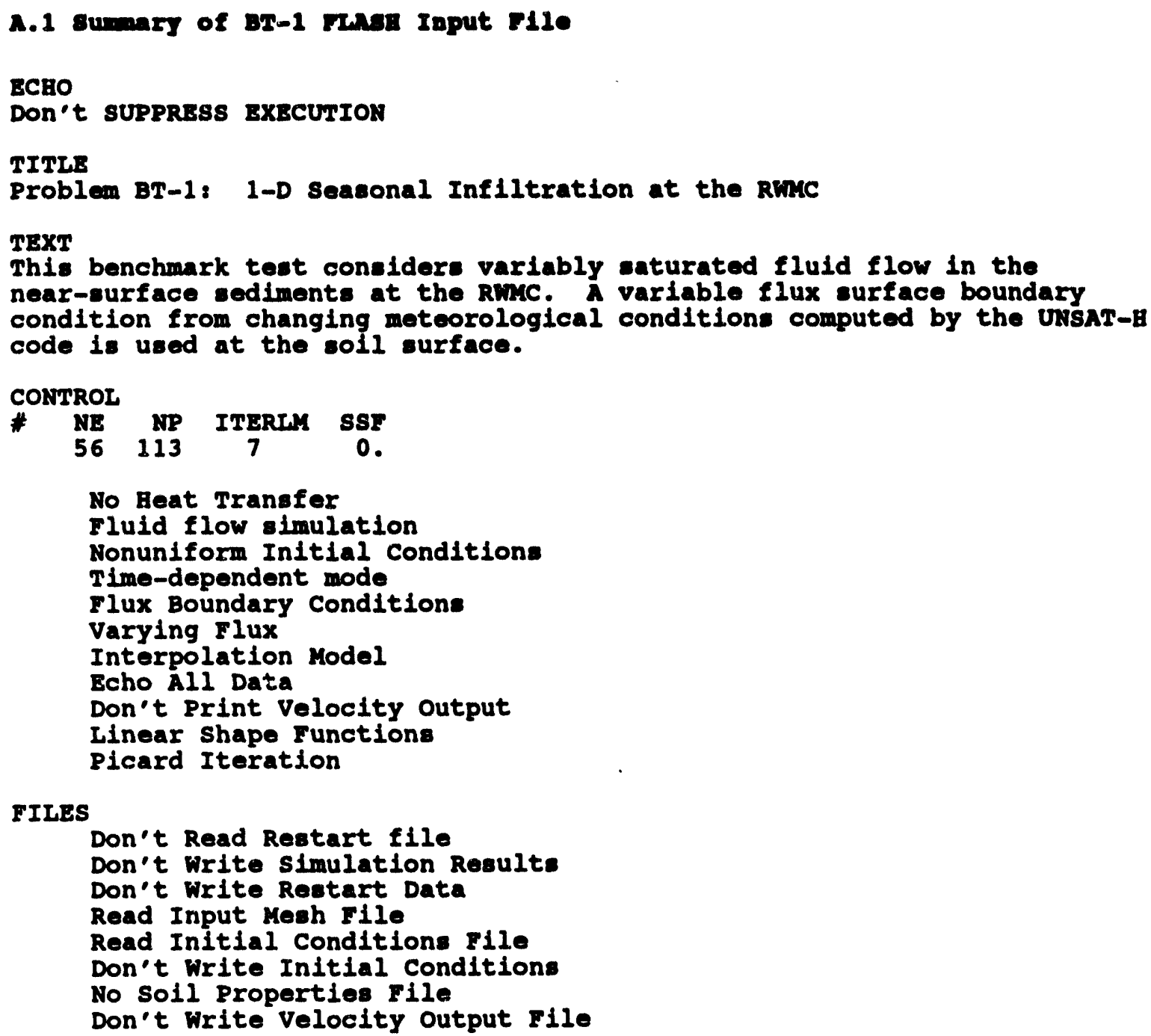




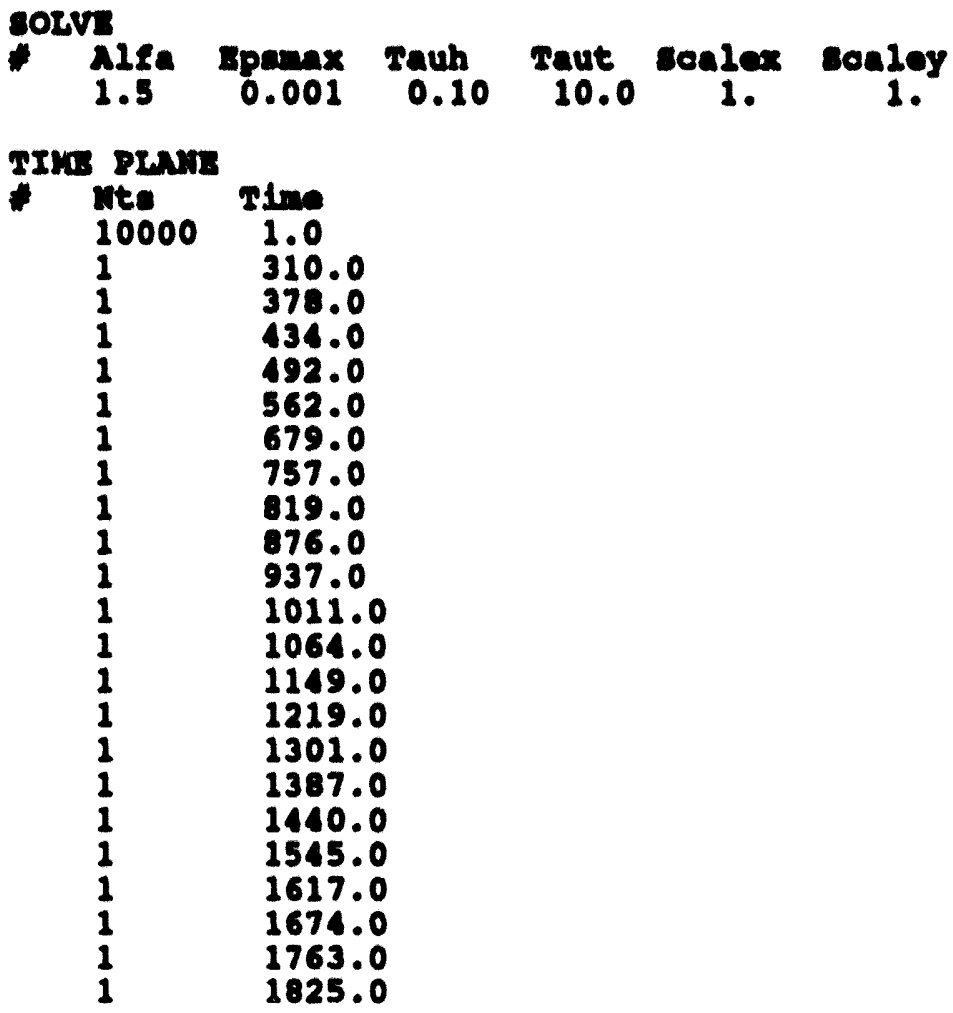

FIUXBC

$\begin{array}{lll}1 & 10.0 & .0 \\ 2 & 10.0 & .0 \\ 3 & 10.0 & .0 \\ 4 & 10.0 & .0\end{array}$

(Inee onfted)

$$
\begin{array}{lll}
1821 & 10.0 & .0 \\
1822 & 10.0 & .0 \\
1823 & 10.0 & .0 \\
1824 & 10.0 & .0 \\
1825 & 10.0 & .0
\end{array}
$$

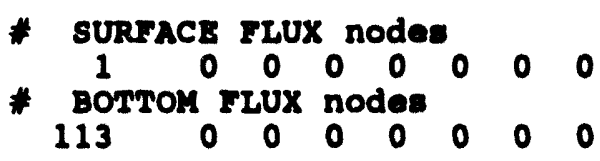

\begin{tabular}{|c|c|}
\hline teky & Poros \\
\hline $\begin{array}{l}1.722 z-04 \\
1.333 z-04 \\
9.722 z-05 \\
5.833 z-05\end{array}$ & $\begin{array}{l}0.510 \\
0.507 \\
0.503 \\
0.500\end{array}$ \\
\hline
\end{tabular}

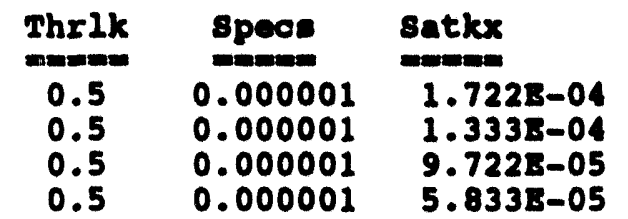

TABLES

* Material properties for so11 1 (eilt from will w06 $1.7-2.7$ ft)

0.000000B-05 5.100000B-01 1.000000B+00 
2.5000008-01

$2.8442035-01$

$5.0998592-01$

5.0998278-01

(rlaes cultted)

$6.7910705+04$

$7.7260728+04$

1.2752898-01

1.2697808-01

$9.999997 \mathrm{~B}+04$

1.2599418-01

TNDTES

* Material propertios for 1011

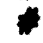

$0.0000008-05$

2.5000008-01

2.8442038-01

Thote

5.0700008-01

5.0698898-01

5.06986418-01

\section{(Ifloos onitted)}

$6.7910708+04$

$7.7260728+04$

$9.9999978+04$
1.3524068-01 1.3464208-01 $1.3357228-01$

\section{$9.3596628-01$}

$9.3089322-01$

1.0812288-11

$6.8431408-12$

2.8188458-12

\section{TABLES}
Material pro
$8 h 1$
$0.0000008-05$
$2.5000008-01$
$2.844203 \mathrm{~s}-01$
$(2$
(2)
$6.791070 \mathrm{~s}+04$
$7.726072 \mathrm{~s}+04$
$9.9999978+04$
$1.4213558-01$
$1.4147698-01$
$1.4029878-01$
3.7159188-11
2.3714668-11
9.7799628-12
TABLES
* Material
8hi
$0.0000008-05$
$2.5000008-01$
5.0300008-01
Relk
$2.5000008-01$
$2.8442038-01$
$5.0299165-01$
$1.0000008+00$
9.4375358-01
5.0298975-01 9.3946903-01
(Ilaes Oaltted)

\section{(Lines ondted)}
$6.7910708+04$
$7.7260728+04$
1.5031778-01
$9.999997 \mathrm{~B}+04$
1.4957958-01
1.4825768-01
8.1009038-11
5.2158098-11
2.1307908-11

1.9085938-11

1.2260878-11

5.0534638-12

\section{Reik}

$1.0000002+00$

.

$9.3487508-01$

OUTPUT

Bcho all Input Data 


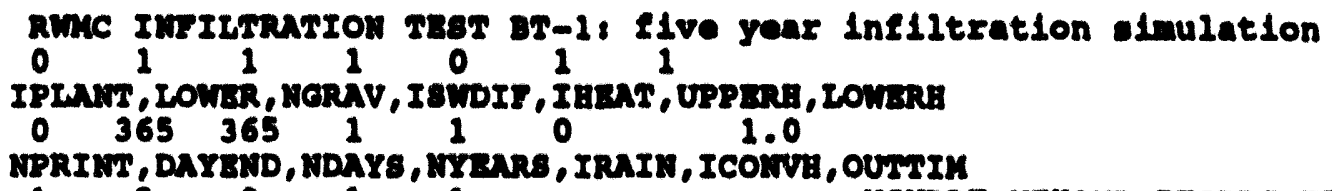

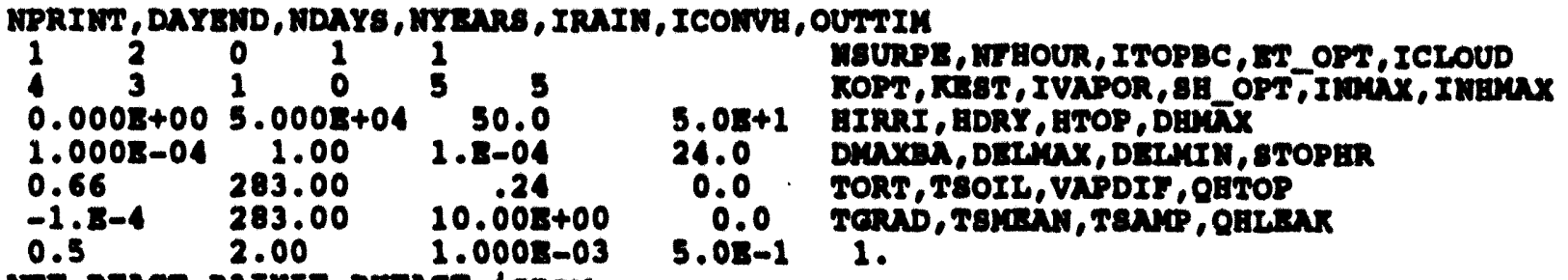

WTE, RLACT, RAINIF, DHACT, Ionow

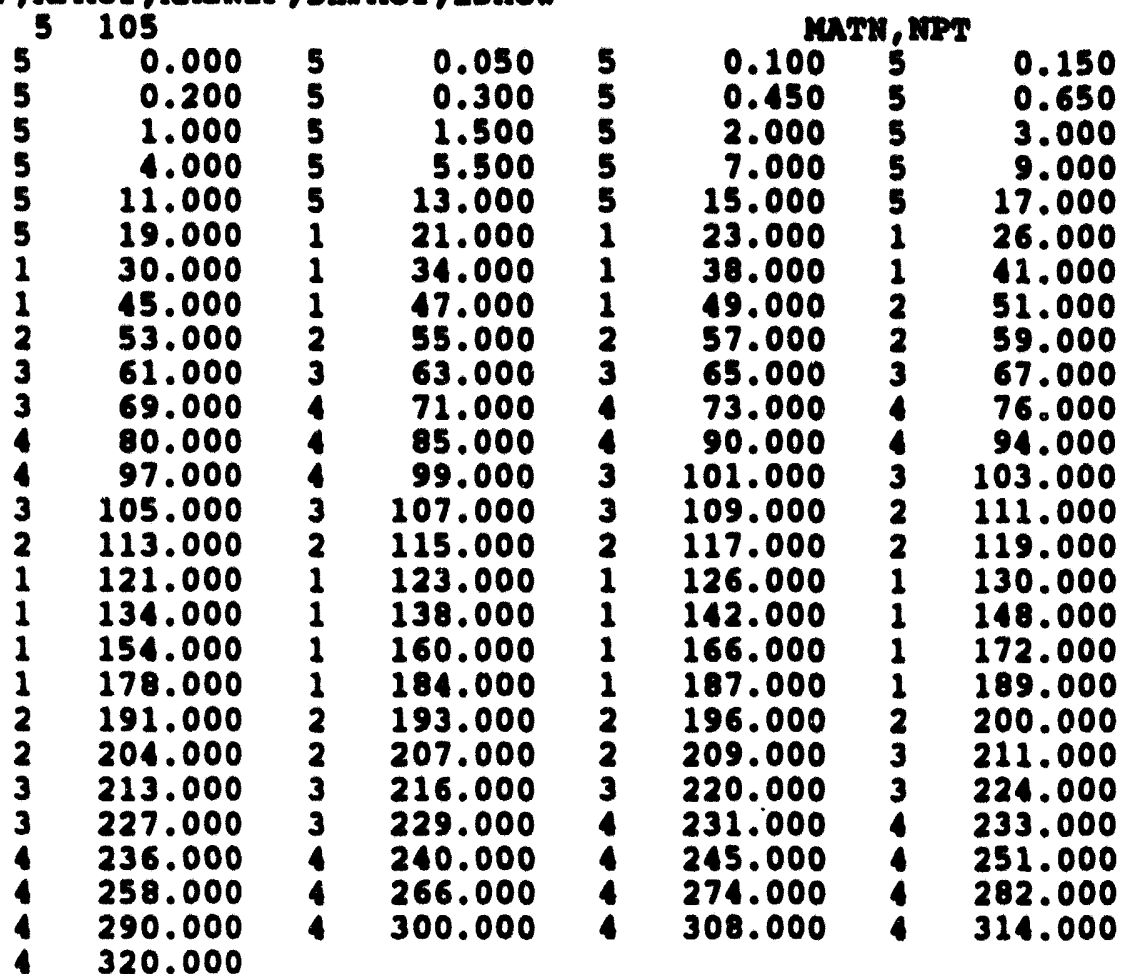

soli Number 1 (8ILT: Erom well w06, 1.7-2.7 ft In Mcslroy and Bubbe11, 1990) $\begin{array}{llll}0.51 & 0.12 & 0.01197 & 1.58911\end{array}$

soil Number 1

$\begin{array}{lllll}2.000 & 0.6200 & 0.01197 & 1.58911 & 0.5\end{array}$

soil Number 2 ( $1 / 3$ of way between 11 and $\$$ below) $\begin{array}{llll}0.507 & 0.127 & 0.01033 & 1.58461\end{array}$

so11 Number 2 $\begin{array}{lllll}2.000 & 0.4800 & 0.01033 & 1.58461 & 0.5\end{array}$

soll Number 3 ( $2 / 3$ of way between 1 and 4 below) $\begin{array}{llll}0.503 & 0.133 & 0.00869 & 1.58011\end{array}$

So11 Number 3 $\begin{array}{lllll}2.000 & 0.3500 & 0.00869 & 1.58011 & 0.5\end{array}$

soll Number 4 (SILT, from well N06, 11.0-11.8 ft in Mcslroy and Bubbel1, 1990) $\begin{array}{llll}0.50 & 0.14 & 0.00705 & 1.57561\end{array}$

Soll Number 4 $\begin{array}{lllll}2.000 & 0.2100 & 0.00705 & 1.57561 & 0.5\end{array}$

Soll Number 5 (SILT, from well $106,1.7-2.7$ it in McElroy and Hubbe11, 1990) $\begin{array}{llll}0.51 & 0.12 & 0.01197 & 1.58911\end{array}$

So11 Number 5 


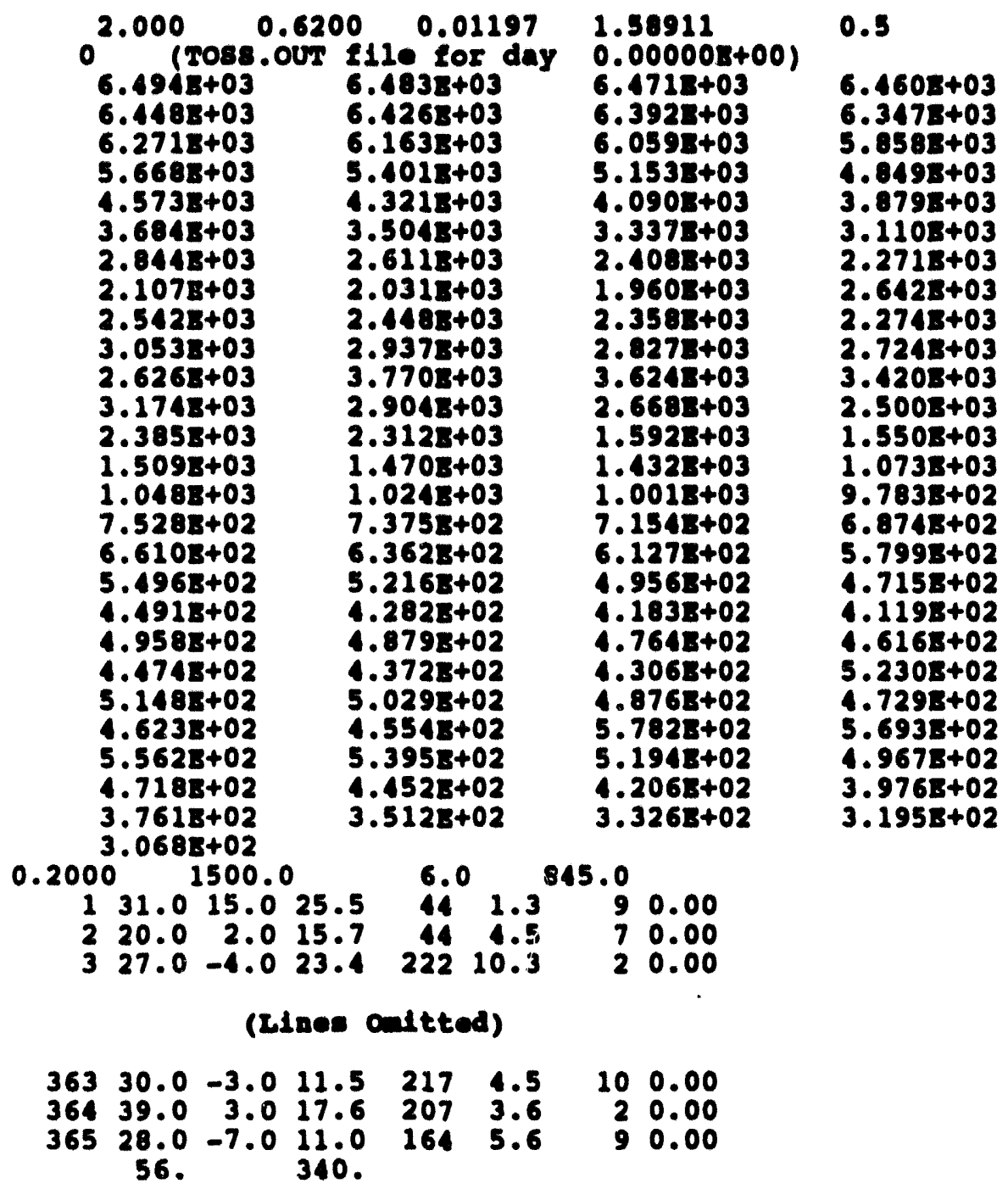

MoNX (UT8AT-B V2.0) 


\section{A.3 eumary of Br-2 rugu Input rile}

\section{BCEO}

DOn't sUPPREss EXscurIOH

\section{TITLS}

Problew BT-2, 2-D Free surface Flow and Transport

\section{T25T}

This benohmark test considers additional infiltration from water diverted to the spreading areas from the divereion of the Blg rost River. This deok modele the Initlal high 21 lux period. Two more rune are made, one with a lower flux followed by a sero flux redietribution poriod.

CONTROR

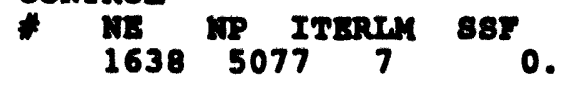

Ho Beat Transefor

Fluid flow elmulation

Borisontul flow equation

Days

Dupuit

Mon-Uniform Initial conditions

Time-Dependent Mode

Mixed Boundary Conditione

mipirical Model

Scho All Data

Don't Print Velocity Output

FILES

Don't Read Restart flle

Don't Write simulation Resulte

Don't Write Restart Data

Read Input Meah File

Read Initial Conditions File

write Initial conditions (afterwards)

No soll Properties File

Don't Write velocity Output File

\section{soLvs}

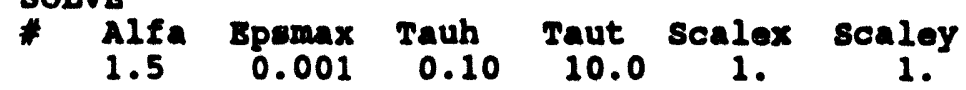

TIME PLANE

$\begin{array}{ll}\text { * Nts } & \text { Time } \\ 10000 & 31.0 \\ 1 & 365.0 \\ 1 & 730.0 \\ 1 & 1096.0\end{array}$

FIXEDBC

* TOp 79 nodes

$\begin{array}{llllllllll}3210 & 0 & 1 & 0 & 197.92 & 0 & 0 & 0 & 0 & 0 \\ 3211 & 0 & 1 & 0 & 197.92 & 0 & 0 & 0 & 0 & 0 \\ 3212 & 0 & 1 & 0 & 197.92 & 0 & 0 & 0 & 0 & 0\end{array}$

\section{(Ilnos onltted)}

$\begin{array}{llllllllll}4949 & 0 & 1 & 0 & 197.92 & 0 & 0 & 0 & 0 & 0 \\ 5076 & 0 & 1 & 0 & 197.92 & 0 & 0 & 0 & 0 & 0\end{array}$ 


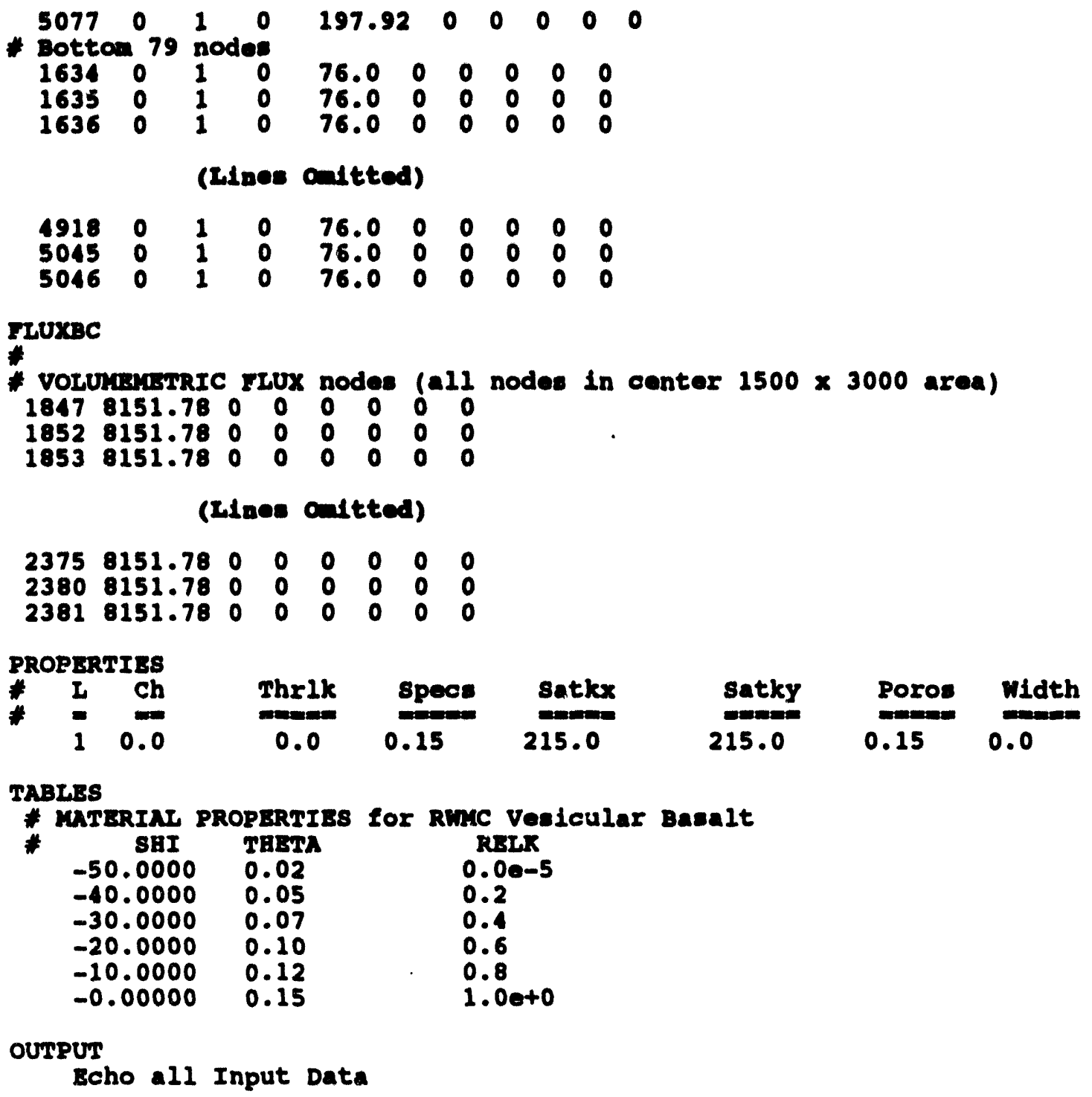

PROPERTIES

$\begin{array}{rrrrrrrr}* & \text { I } & \text { Ch } & \text { Thrlk } & \text { Specs } & \text { satkx } & \text { satky } & \text { Poros Width } \\ * & =0.0 & 0.0 & 0.15 & 215.0 & 215.0 & 0.15 & 0.0\end{array}$

TABLES

* MTERIAT PROPERTIEs for Rinc Vesicular Basalt

*

$-50.0000$

$-40.0000$

$-30.0000$

$-20.0000$

$-10.0000$

$-0.00000$

THETS

0.02

0.05

0.07

0.10

0.12

0.15

OUTPUT

RSLK

0.0 - 5

0.2

0.4

0.6

0.8

1. Oe+o

Bcho all Input Data 


\section{A.4 sumary of BI-2 PORIon Input File}

TITLe: FIASE benchmark problem two. A crude approximation to the effects from $f$ increased infiltration due to high water years and water being diverted from

f the Big Lost river to the spreading areas and then infiltration down to the / water table. Oberservations nearby wells showed that the infiltration event

$f$ caused almost a 90 degree ohift in the direction of flow beneath the Rirc.

1

$$
\text { / }
$$

I

GRID 83 by 87

I

coordinate $x:$

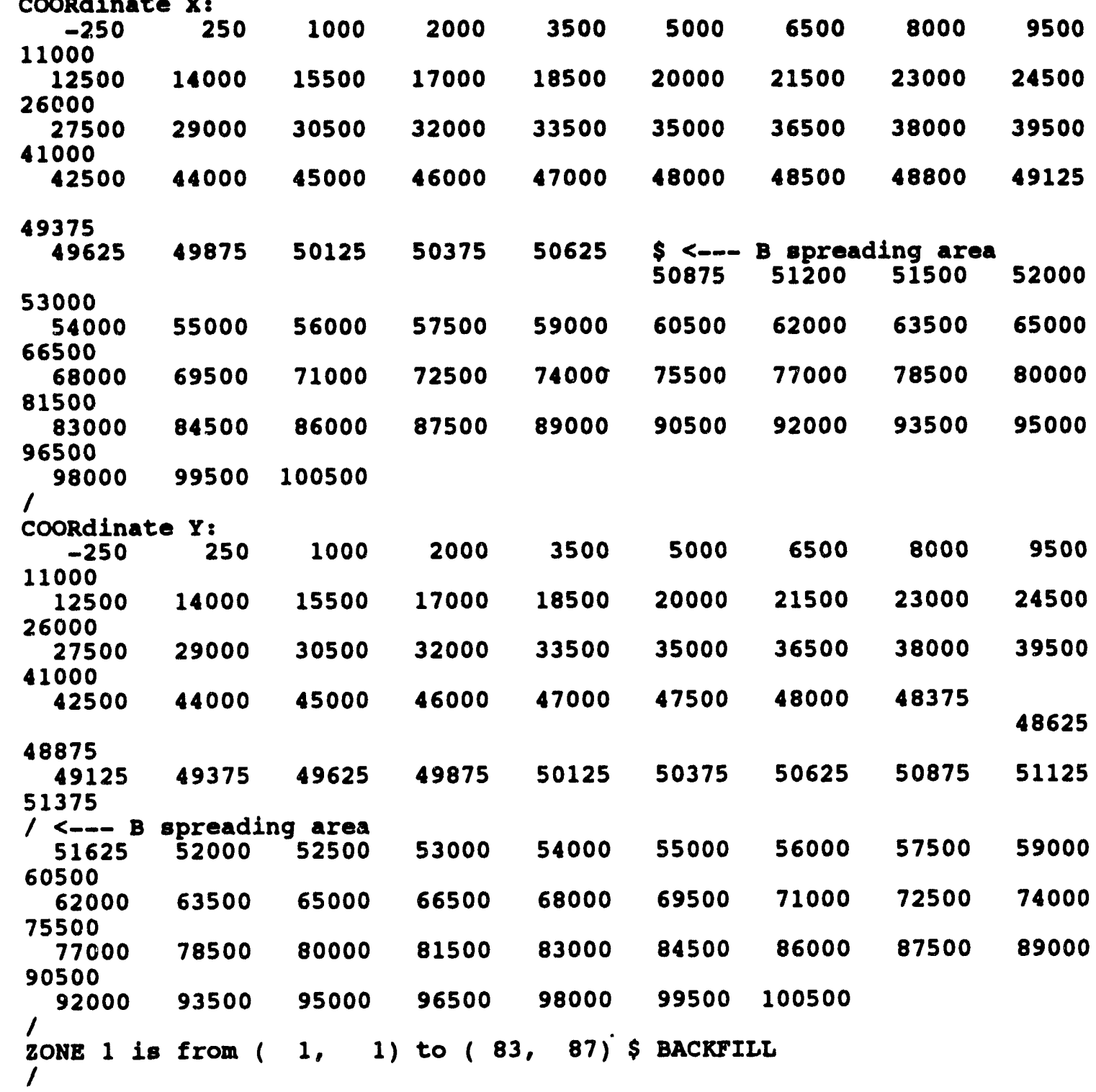


DENSity of fluid is constant and equal to $1000 . \mathrm{kg} / \mathrm{m} * \mathrm{~m} * \mathrm{~m}$ 1

READ 1 te record from 'end.es'

I

FOR 1 Gasalts in the saturated zone

MATErial PROPerties: rho $1.90 \mathrm{gm} / \mathrm{cc}$, neff $=0.150$, ntot $=0.150$, ndif $=$ 0.150

GYDRaulic prop. $88=1.0-3, \mathrm{xx}=215.0, \mathrm{Ky}=215.0 \mathrm{~m} / \mathrm{day}$

I

BOUN P -1 FLUX $=0$.

BOUN P +1 FLUX $=0$.

BOUN $P$-2 VALU $=76.00$ \$ equivalant to 4150 feet

BOUN P +2 VALU $=197.92$ \$ equivalant to 4550 feet

I

LOCAte subregion $(1,1)$ to $(83,87)$ with ID-TOTL

LOCAte subregion $(40,39)$ to $(45,50)$ with ID=SPRDing area $b$. 1

$/$ influx from the time period of 1982-1985

sOURce for $P$ : volume of 0.13224 for ID=SPRDing area $b$

1

I OPERATIONAL CONTROL

PROPerty or $P$ is HARY mean

MATRIX in $X$ and $Y$ directions for $P$ in 2 sweeps using ADI

PROBlem with FREE SURFace in AREAl mode

CONVergence for $P_{;}$LOCAl mode; value $=1.00-04, \max$ of 1 iterations

CONVergence for FLOW RBFBerence; LOCAl mode; val = 1e-3, max of 3 iterations I

DIAGnostic node at $(30,40)$ every 5 stieps

OUTPut every 100000 steps

/

FLUX BALAnce for $P$ in 'flux.out' for ID-TOTL every 50 steps

FLUX BAIAnce for $P$ fOr ID=SPRD every 50 ateps

Solv for $P$

900000

SAVE U V P

31 in AUTO 1e-3 inc $1.11 \mathrm{max}$

$0.5 \min 1 . e-52.0$

I

solv for $P$

900000

SAVE U V P

1

solv for $P$

900000

SAVE U V P

I

Solv for $P$

900000

SAVE U V P

5 Now in 'end. 0 '

334 in AUTO $1 e-2$ inc $1.11 \max 3.5 \mathrm{~min} 1.0-42.0$

I

/ influx from the time period of 1985-1987

souRce for $P$ ID=SPRDing area $b$ OFF

souRce for $P$ : volume of 0.02952 for ID=SPRDing area $b$

I

SOLV for $P$

900000

SAVE U V P

I

SoLv for $P$

900000

SAVE U V P

$s$ Now in 'end.0' \$ end of 1982

365 in AUTO $1 e-2$ inc $1.11 \mathrm{max} 3.5 \mathrm{~min} 1 . e-42.0$

5 Now in 'end.0' \$ end of 1983

366 in AUTO $1 e-1$ inc $1.11 \max 3.5 \mathrm{~min} 1 . e-42.0$

5 Now in 'end.1' \$ end of 1984

I

365 in AUTO le-1 inc $1.11 \mathrm{max} 3.5 \mathrm{~min} 1 . e-42.0$

5 Now in 'end.1' \$ end of 1985

365 in AUTO 1 e-1 inc $1.11 \max 3.5 \mathrm{~min} 1 . e-42.0$

S Now in 'end.1' \$ end of 1986 


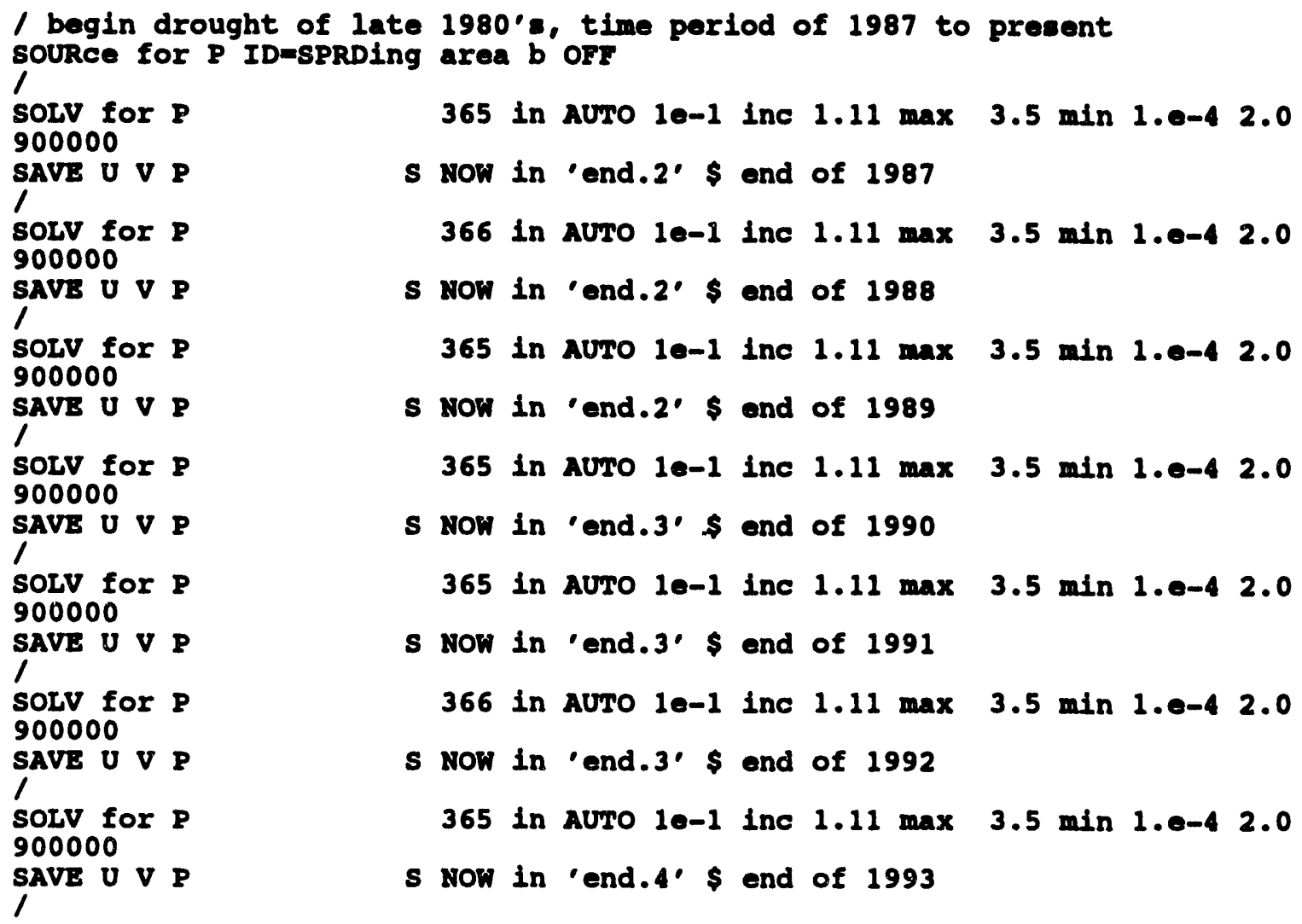




\section{A.5 sumary of BT-3 Fugn Input File}

\section{BCHO}

\section{TITLE}

Problem BT-2: 2-D sinulation of transient infiltration from surface ditcher

\section{TEXT}

This benchmark test simulates an open drainage ditch filled with water during the epring runoff and dry the remainder of the year. The oimulation domain is a 2-D fractured bacalt with a gedimentary interbed and edimentary arface soll. The top boundary is set to background flux of $5 \mathrm{~cm} / \mathrm{year}$. During the flooding events the boundary above the ditch is held eaturated. The bottom boundary was set to a fixed value of $-30 \mathrm{~cm}$ of head. The lateral boundaries of the domain are no flux. A transient elmulation to eteady-etate conditions is firet run, then a set of sinulations which consider a 5 year cycle of flooding over a 2 week period is run. Background infiltration is considered the remainder of the year.

\section{CONTROL}

\# NE $\begin{array}{cccc}\text { NP } & \text { ITERIM } & \text { SSF } \\ 3570 & 9528 & 7 & 0 .\end{array}$

Transient simulation mode

* Steady etate imulation mode No Beat Transfer

Fluid Flow simulation

Cartesian Coordinates

nonUniform Initid Conditions

Mixed Boundary Conditions

Constant Flux Input Data

Don't Echo of ali Input Data

Don't Pxint Velocity Data

Modified Picard

Iinear Basis functions

FILES

Don't Read Restart Input

Don't Write Restart output

Write Simulation Results

Read Mesh Input

Read Initial Conditions

Write Initial Conditions

Read Soil Properties

Don't Write Velocity Output

SOLVE

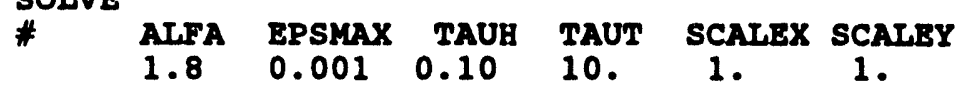

TIME PLANE

$\begin{array}{cc}\text { * NTS } & \text { TIME } \\ \text { * flooding on } & \\ 1000 & 7.00 \\ 1 & 14.00\end{array}$

\section{FIXEDBC}

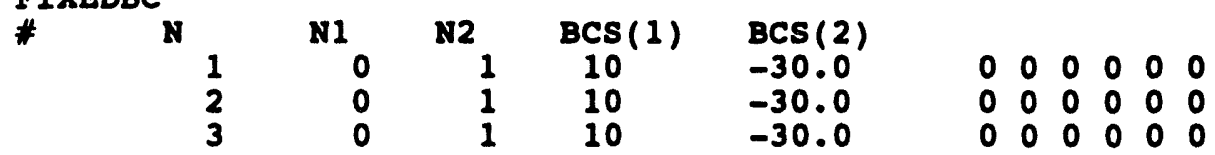




\section{(Iines onltted)}

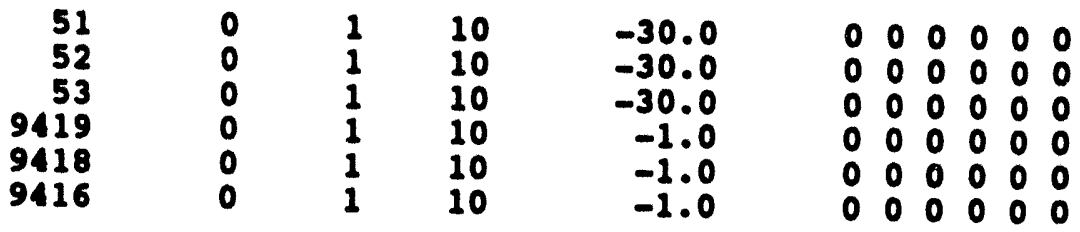

(ulnes ondtted)

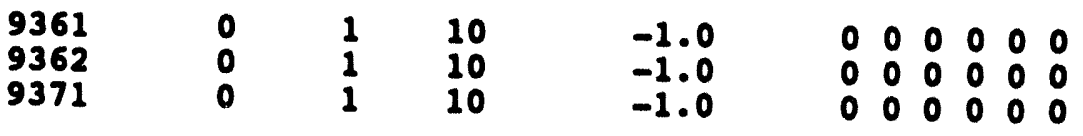

FLUXBC

* ATr ATr

0. $1.585 e-7$

"SURACE FLUX NODES

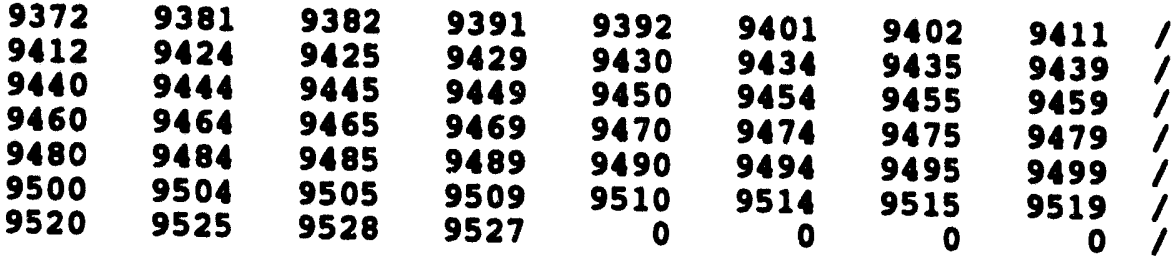

\#BOTYOA FLUX NODES

$$
00
$$

PROPERTIES

* I
*
1
2
3
4
5

$\begin{array}{ccc}\text { Ch } & \text { Thrlk } & \text { Specs } \\ 0.5 & 0.5 & 0.100 \\ 0.5 & 0.5 & 0.100 \\ 0.5 & 0.5 & 0.100 \\ 0.5 & 0.5 & 0.100 \\ 0.5 & 0.5 & 0.010\end{array}$

Satks
$7.590 \mathrm{~B}-5$
$1.000 \mathrm{~B}-4$
$1.160 \mathrm{~B}-5$
$9.840 \mathrm{~B}-2$
$7.590 \mathrm{~B}-5$

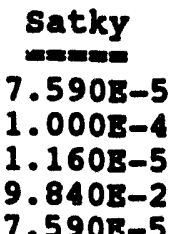

Poros Width

0.480 and

$0.228 \quad 1$.

0.1451.

$0.500 \quad 0.5$

OUTPUT

Bcho all Input Data 


\section{A.6 swang of Dr-4 posiron Input rile}

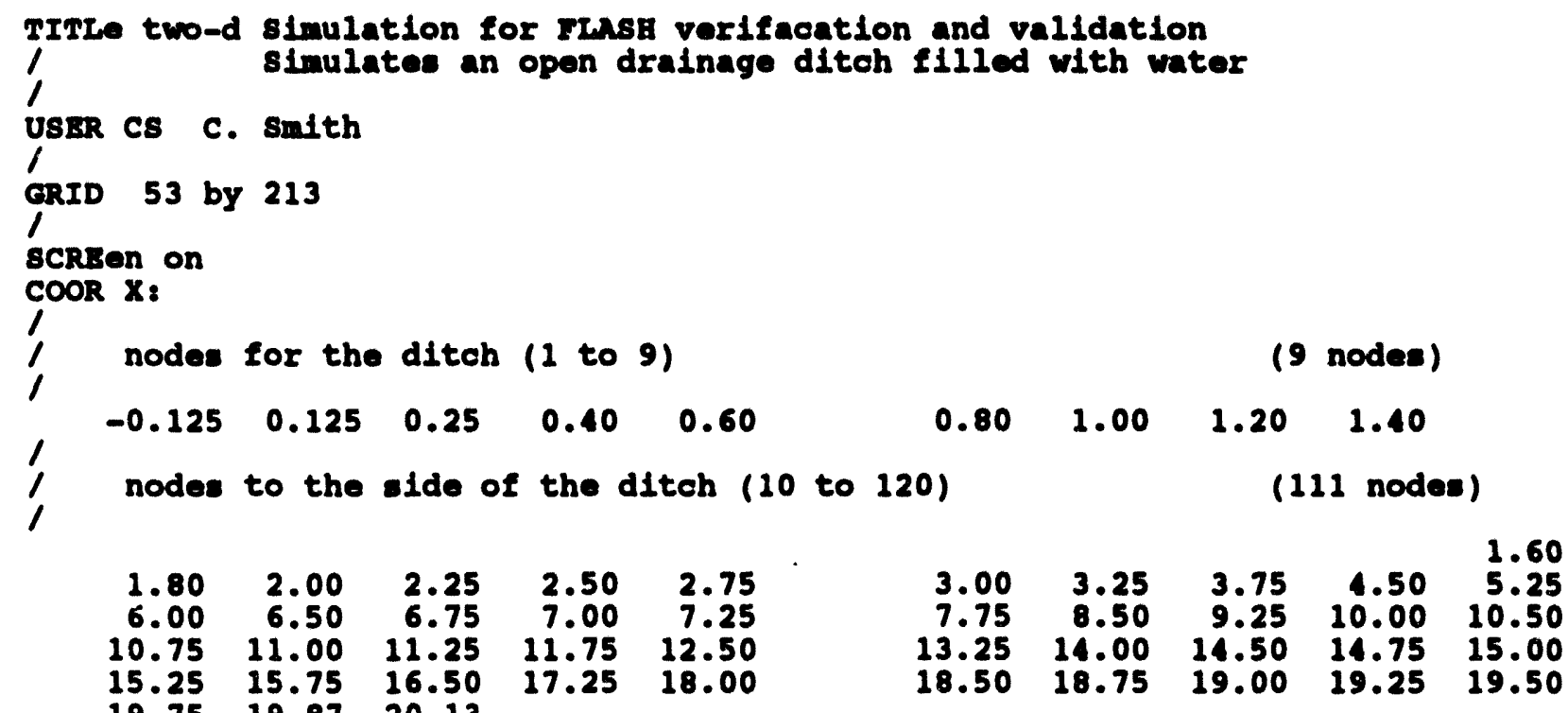

COOR Y:

COOR Y:$$
\text { / }
$$

(32 nodes)

$\begin{array}{rrrrr}-0.15 & 0.15 & 0.45 & 0.80 & 1.20 \\ 4.20 & 4.70 & 5.20 & 5.70 & 6.20 \\ 8.80 & 9.00 & 9.15 & 9.30 & 9.45 \\ 9.93 & 9.98 & & & \end{array}$

$\begin{array}{ll}1.70 & 2.20 \\ 6.70 & 7.20 \\ 9.60 & 9.70\end{array}$

Nodes for 110' Sediment Interbed (33-51)

$\begin{array}{lllll}10.57 & 10.70 & 10.02 & 10.06 & 10.10 \\ 11.48 & & & 11.05 & 11.17\end{array}$

\subsection{10 \\ 9.83}

9.77

(19 nodes)

Nodes for Massive Basalt (52 - 82)

/

$\begin{array}{lllll}12.30 & 11.52 & 11.56 & 11.60 & 11.65 \\ 14.30 & 14.50 & 12.70 & 12.90 & 13.10 \\ 15.74 & 15.78 & 14.70 & 14.90 & 15.10\end{array}$

1

Nodes for vesicular basalt ( 83 - 184)

$\begin{array}{lllll}16.25 & 16.35 & 16.47 & 16.60 & 16.75 \\ 17.65 & 17.80 & 17.95 & 18.10 & 18.25 \\ 19.50 & 19.75 & 20.00 & 20.25 & 20.50 \\ 22.00 & 22.25 & 22.50 & 22.75 & 23.00 \\ 24.50 & 24.75 & 25.00 & 25.25 & 25.50 \\ 27.00 & 27.25 & 27.50 & 27.75 & 28.00 \\ 29.50 & 29.75 & 30.00 & 30.25 & 30.50 \\ 32.00 & 32.25 & 32.50 & 32.75 & 33.00 \\ 34.50 & 34.75 & 34.95 & 35.10 & 35.25 \\ 35.74 & 35.77 & 35.79 & 35.81 & \end{array}$

1

/ nodes for surficial sediments (185 - 213)
10.15 11.26

10.20
11.30
$10.27 \quad 10.35$

$\begin{array}{lll}0.27 \quad 10.35 & 10.45\end{array}$

$1.1 .3511 .40 \quad 11.44$

(31 noder)

$\begin{array}{lllll}11.70 & 11.77 & 11.85 & 11.95 & 12.10 \\ 13.30 & 13.50 & 13.70 & 13.90 & 14.10 \\ 15.30 & 15.45 & 15.50 & 15.60 & 15.68\end{array}$

(117 nodea)

$\begin{array}{lllll}15.95 & 16.00 & 16.05 & 16.10 & 16.17 \\ 16.90 & 17.05 & 17.20 & 17.35 & 17.50 \\ 18.45 & 18.65 & 18.85 & 19.05 & 19.25 \\ 20.75 & 21.00 & 21.25 & 21.50 & 21.75 \\ 23.25 & 23.50 & 23.75 & 24.00 & 24.25 \\ 25.75 & 26.00 & 26.25 & 26.50 & 26.75 \\ 28.25 & 28.50 & 28.75 & 29.00 & 29.25 \\ 30.75 & 31.00 & 31.25 & 31.50 & 31.75 \\ 33.25 & 33.50 & 33.75 & 34.00 & 34.25 \\ 35.40 & 35.50 & 35.58 & 35.65 & 35.70\end{array}$

(29 nodes) 


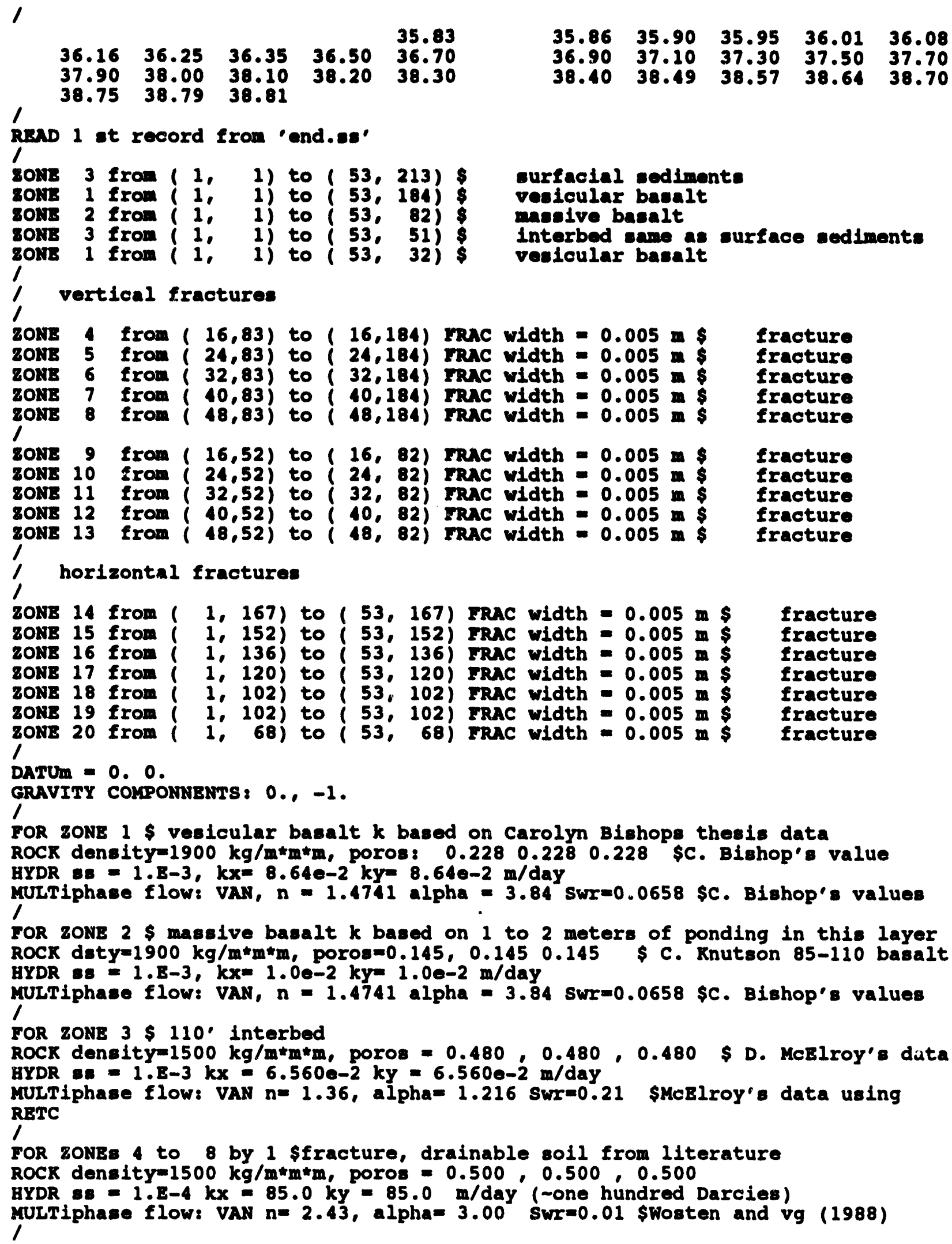

fracture Eracture fracture fracture fracture

Eracture Eracture fracture fracture Eracture I 
FOR 8ONEe 9 to 13 by 1 \$fracture, lese soll fron 11terature

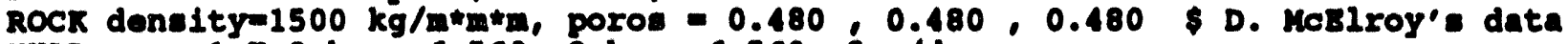
BYDR $=1.8-3 \mathrm{kx}=6.5600-2 \mathrm{ky}=6.5600-2 \mathrm{~m} / \mathrm{day}$

NUITIphase flow: VN $n=1.36$, alpha 1.216 swrm0.21 sMoslroy's data using RETC

I

FOR zONE 14 to 20 by 1 \$fracture, drainable coll from 11terature

ROCK denelty $1500 \mathrm{~kg} / \mathrm{m}^{* m * \mathrm{~m}}$, poros $=0.500,0.500,0.500$

GYDR $=1 . \mathrm{s}-4 \mathrm{kx}=85.0 \mathrm{ky}=85.0 \mathrm{~m} / \mathrm{day}$ (-one hundred Daroies)

MULTiphase flow: vai $n=2.43$, alpha 3.00 swre0.01 shosten and vg (1988)

I

BOUN $P-1$ FIUX $=0$

BOUN $P+1$ FIUX $=0$.

BOUN $P-2$ NODE $=-0.3$

BOUN $P+2$ INTE $=38.79$ dumny number $=1(1,213)$ to $(9,213)$

Boun $P+2$ FIUX $-1.370-4$ duny number $=1(10,213)$ to $(91,213)$

PROPerty options: GzOKetric mean

MATRix in $X$ and $Y$ direction for $P$ in aweepe using ADI

COrvergence for $P_{8}$ LOCNI mode; value $5 . e-4$ max iterations is 7

coint

FLUX Bara for $p$ in 'flux.out' $\operatorname{from}(1,213)$ to $(91,213)$ every 500 eteps

FIUX BATA for

Iros $(1,83)$ to $(91,184)$ every 500 otepe

FIUX BAnA for $P$

from $(1,52)$ to $(91,82)$ every 500 atepa

FLUX BAIA for $P$

from $(1,33)$ to $(91,51)$ every 500 atepa

I

DIAGnostic node at 15,150 print every 1 stepe

WINDOW from 2,2 to 2,2

ourput every 900000 etepe

1

/SOLVe for $P$ 365.0 days eteps 0.01 inc $1.005 \mathrm{mx} 0.02$ mn $1.0-31.1900000$
/SAVE U V S Nov in 'end.0'

1

/Solve for $P \quad 365.0$ days steps 0.01 inc $1.005 \mathrm{mx} 0.02 \mathrm{mn} 1.0-31.1900000$

/SAVE U $V$ P $S$ Now in 'end. $0^{\prime}$

I

/sorve for $P$

/SAVE U $Q$ P

365.0 days oteps 0.02 inc Now in 'end. $0^{\prime}$

/solve for $P$

/solve for $P$

/ SAVE U $\mathrm{P} s$

365.0 days steps 0.03 inc

365.0 days teps 0.04 inc

1

/solve for $P$

/solve for $P$

/SAVE U V P S

1

/sorve for $P$

/solve for $P$

/SAVE U V P S Now in 'end. 1'

I

/solve for $\mathrm{P}$

/solve for $P$

/SAVE U V P S

365.0 days steps 0.05 inc

365.0 days steps 0.07 ine Now in 'end. 1'

365.0 days steps 0.10 inc 365.0 days steps 0.20 inc Now in 'end. 1'

in end. 1

I

/solve for $P$

/solve for $P$

/SAVE U V P S

365.0 days eteps 0.40 inc

365.0 days steps 0.70 inc Now in 'end. 2 '

720.0 days steps 1.00 inc

720.0 days steps 1.50 inc

$1.005 \operatorname{mx} 0.03 \operatorname{mn} 1.0-31.1900000$

$1.005 \mathrm{mx} 0.04$

mn $1.0-31.1900000$

$1.005 \mathrm{mx} 0.05 \mathrm{mn} 1 . e-31.1900000$

$1.005 \mathrm{mx} 0.07$ mn $1.0-31.1900000$

$1.005 \mathrm{mx} 0.10 \mathrm{mn} 1.8-31.1900000$

I

/RELAxation factor for $P$ is 0.5

1

/SOLVe for $P$ in STEAdy state mode maximum steps $4000 \mathrm{~min}$ steps 200

$1.005 \mathrm{mx} 0.20 \mathrm{mn} 1.0-31.1900000$

$1.005 \mathrm{mx} 0.40 \mathrm{mn} 1.0-31.1900000$

$1.005 \mathrm{mx} 0.70$

$1.005 \mathrm{mx} 1.00$

$\min 1.0-31.1900000$

$\operatorname{mn} 1.0-31.1900000$

$1.005 \mathrm{mx} 1.50 \mathrm{mn} 1.0-3 \quad 1.1900000$

$1.005 \mathrm{mx} 2.00 \mathrm{mn} 1.0-31.1900000$ Now in "end.2" 
lesve U v p 8 mon in 'and.ese'

1 sorve $p \quad 7.0$ daye auso mode otepe 0.015 Ino $1.2 \mathrm{mx} 5.5 \mathrm{mn} 1.0-3$ de0 2.0 900000

savs U V P \& vor in ' \$100d.1'

1

sorve $P \quad 7.0$ daye auro mode etepe 0.015 inc 1.2 ax 5.5 an $1.0-3$ dec 2.0 900000

gave U 0 \& now in ' 8 lood.1'

I

Bous $P+2$ ILUX $=-1.370-4$

I

solve $\mathrm{P} 51.0$ daye auro mode etepe 0.015 ine $1.2 \mathrm{ax} 5.5 \mathrm{mn} 1.0-3 \mathrm{dec} 2.0$ 900000

savs $U$ V 8 s now in 'drain. 1 '

I

sorve $p 300.0$ daye auro mode atepo 0.020 inc 1.2 wx 5.5 un $1.0-3$ deo 2.0 900000

savs $U$ V 8 ron in 'drain.1'

I

Boun $P+2$ INTS $=38.79$ duwy number $=1$ (1, 213) to $(9,213)$

Bous $P+2$ ruUx $-1.370-4$ duny number $=1(10,213)$ to $(91,213)$

sotve p 7.0 daye auro mode atepe 0.015 inc $1.2 \mathrm{wx} 5.5 \mathrm{mn} 1.0 \mathrm{~m}$ dec 2.0 900000

SAVE $U$ V 8 s wow In ' Ilood.2'

1

sotve $P 7.0$ daye auro mode etepe 0.015 inc $1.2 \mathrm{mx} 5.5 \mathrm{mn} 1.0-3 \mathrm{dec} 2.0$ 900000

savs $U$ V 8 son in ' 1 lood.2'

1

BOUN $P+2$ FLUX $=-1 \cdot 37 e-4$

I

solve P 51.0 daye Auro mode stepe 0.015 inc $1.2 \mathrm{mx} 5.5 \mathrm{an} 1.0-3 \mathrm{dec} 2.0$ 900000

sAvs $U$ V $P$ s non in 'drain.2'

1

SOLVe $P 300.0$ days Auro mode steps 0.020 inc $1.2 \mathrm{mx} 5.5 \mathrm{mn} 1.0-3$ dec 2.0 900000

savs $U$ V $\mathrm{s}$ wow in 'drain.2'

I

BOUN $P+2$ INTE $=38.79$ dumy number $=1(1,213)$ to $(9,213)$

BOUN $P+2$ FIUX $-1.37 e-4$ dumby number $=1(10,213)$ to $(91,213)$ I

sorve $P \quad 7.0$ daye Auro mode tepe 0.015 ine $1.2 \mathrm{mx} 5.5 \mathrm{mn} 1.0-3 \mathrm{dec} 2.0$ 900000

SAvB $U$ V $P$ son in ' Elood. $3^{\prime}$

1

solve $\mathrm{P} 7.0$ daye Auro mode atepe 0.015 inc $1.2 \mathrm{mx} 5.5 \mathrm{mn} 1.0-3 \mathrm{dec} 2.0$ 900000

SAVE U $V$ P Now in ' Elood.3'

I

BOUS $P+2$ FLUX $=-1.37 e-4$

sorve $P 51.0$ days AUTO mode steps 0.015 inc $1.2 \mathrm{mx} 5.5 \mathrm{mn} 1 . e-3$ dec 2.0 900000

SAVE $U$ V P $s$ NOW in 'drain. 3'

1

solve $\mathrm{P} 300.0$ days aUTO mode tepe 0.020 inc $1.2 \mathrm{mx} 5.5 \mathrm{mn} 1.0-3 \mathrm{dec} 2.0$ 900000

SAVE U V P $s$ NOW In "drain.3"

I 


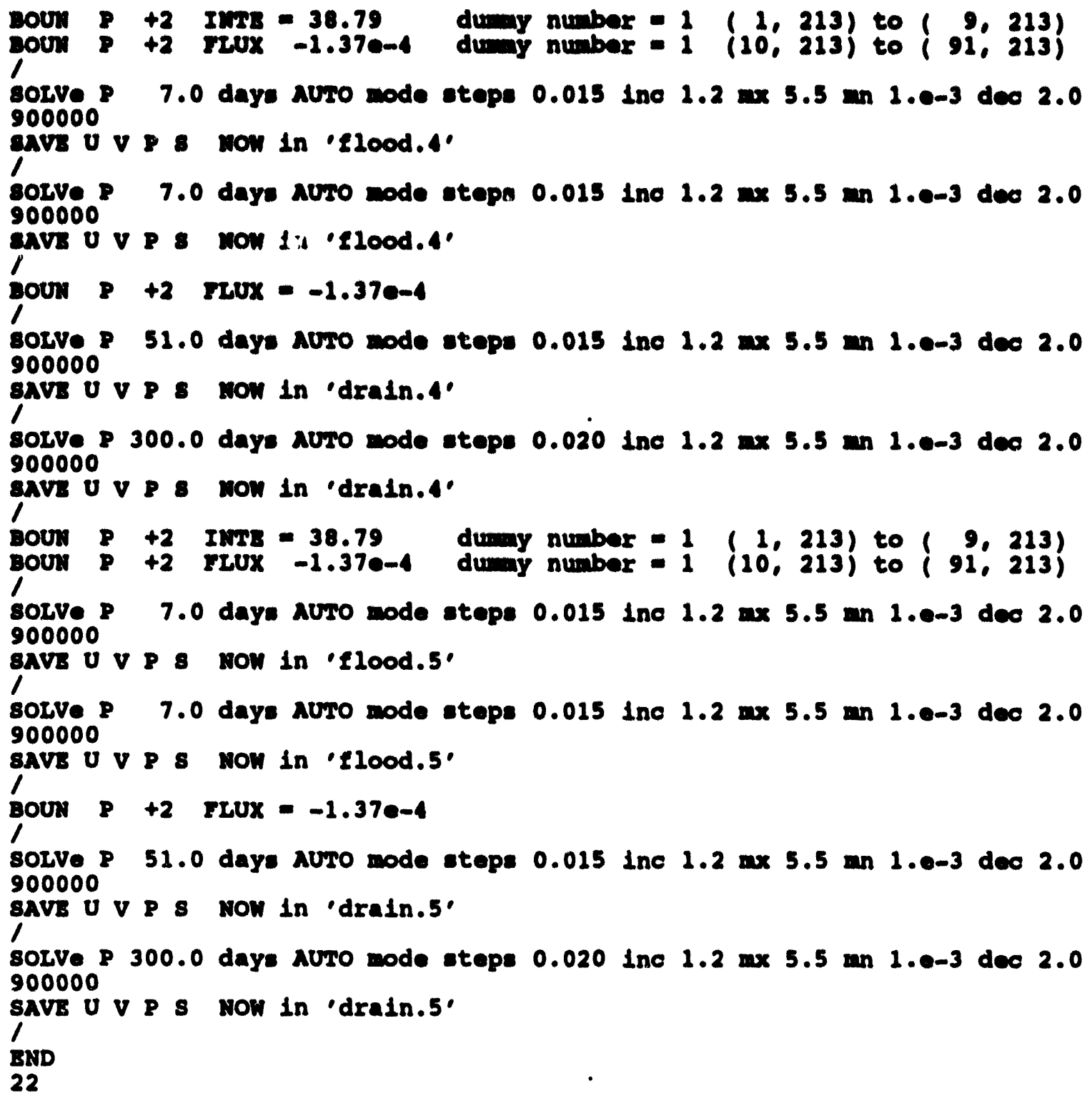



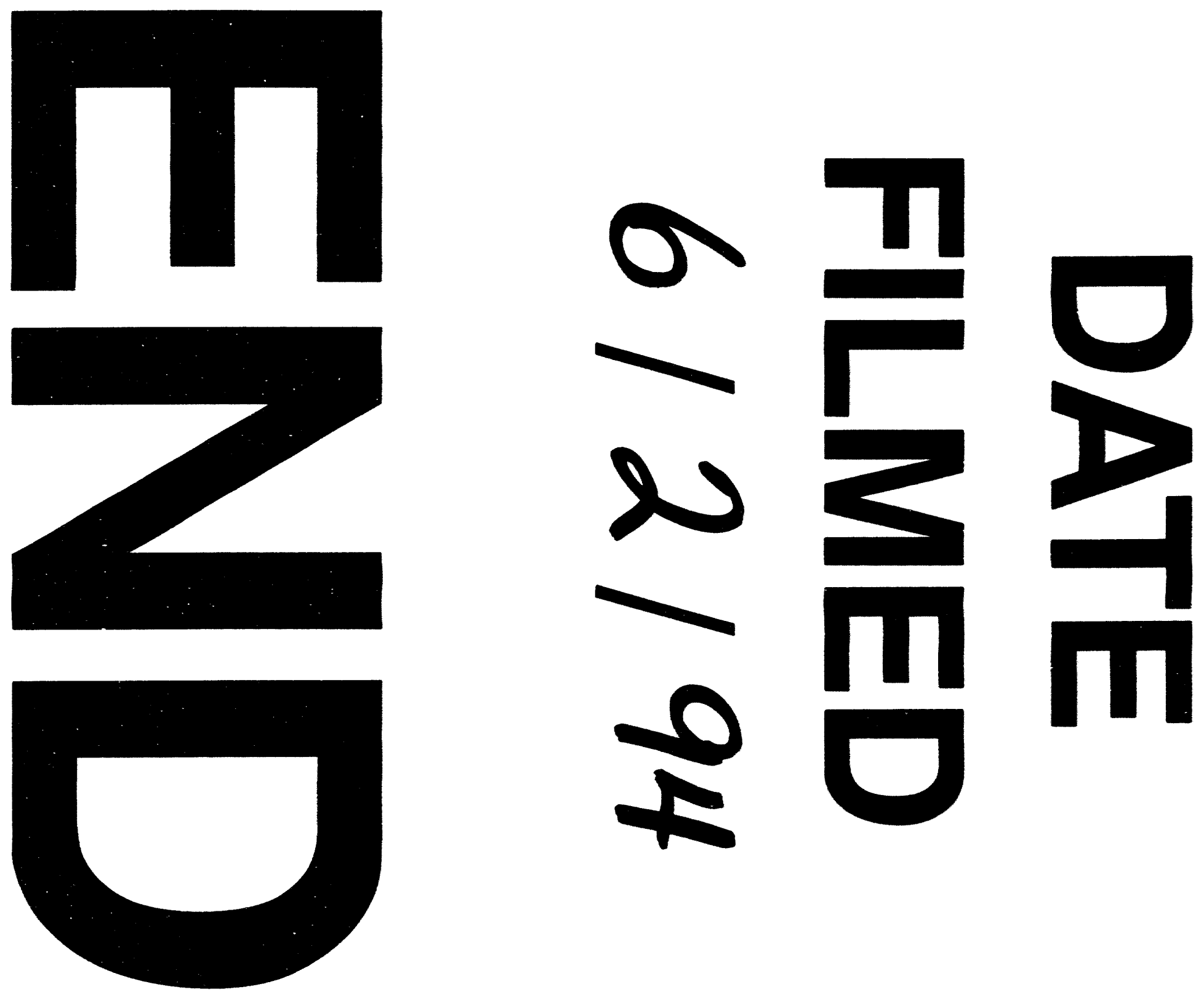
